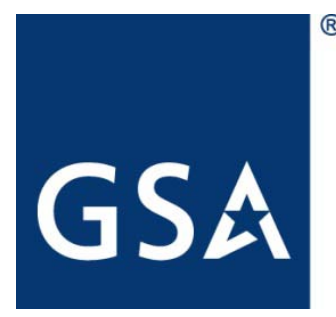

\title{
Achieving Energy Savings with Highly-Controlled Lighting in an Open-Plan Office
}

\author{
Prepared for the \\ General Services Administration \\ by \\ Francis Rubinstein and Abby Enscoe \\ Lawrence Berkeley National Laboratory

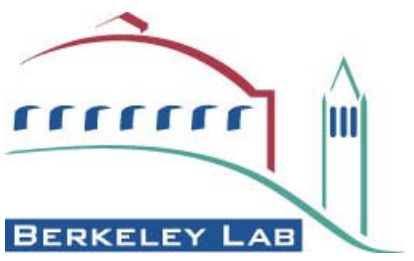




\section{DISCLAIMER}

This document was prepared as an account of work sponsored by the United States Government. While this document is believed to contain correct information, neither the United States Government nor any agency thereof, nor The Regents of the University of California, nor any of their employees, makes any warranty, express or implied, or assumes any legal responsibility for the accuracy, completeness, or usefulness of any information, apparatus, product, or process disclosed, or represents that its use would not infringe privately owned rights. Reference herein to any specific commercial product, process, or service by its trade name, trademark, manufacturer, or otherwise, does not necessarily constitute or imply its endorsement, recommendation, or favoring by the United States Government or any agency thereof, or The Regents of the University of California. The views and opinions of authors expressed herein do not necessarily state or reflect those of the United States Government or any agency thereof or The Regents of the University of California. 


\title{
Achieving Energy Savings with Highly-Controlled Lighting in an Open-Plan Office
}

\author{
Francis Rubinstein, Abby Enscoe \\ Lawrence Berkeley National Laboratory
}

\begin{abstract}
An installation in a Federal building tested the effectiveness of a highly-controlled, workstation-specific lighting retrofit. The study took place in an open-office area with 86 cubicles and low levels of daylight. Each cubicle was illuminated by a direct/indirectpendant luminaire with three 32 watt lamps, two dimmable DALI ballasts, and an occupancy sensor. A centralized control system programmed all three lamps to turn on and off according to occupancy on a workstation-by-workstation basis. Field measurements taken over the course of several monthsd emonstrated $40 \%$ lighting energy savings compared to a baseline without advanced controls that conforms to GSA's current retrofit standard. A photometric analysis found that the installation provided higher desktop light levels than the baseline, while an occupant survey found that occupants in general preferred the lighting system to thebaseline.Simple payback is fairly high; projects that can achieve lower installation costs and/or higher energy savings and those in which greenhouse gas reduction and occupant satisfaction are significant priorities provide the ideal setting for workstation-specific lighting retrofits.
\end{abstract}




\section{Contents}

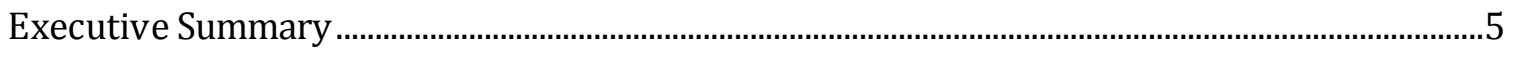

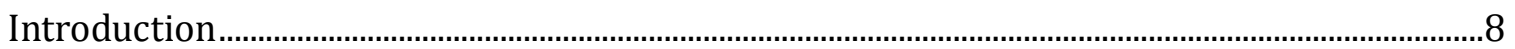

Workstation-Specific Luminaires............................................................................................................

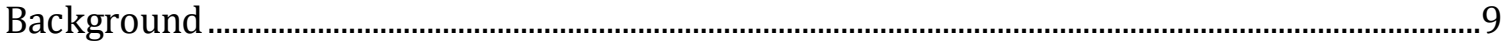

Current Demonstration ............................................................................................................................

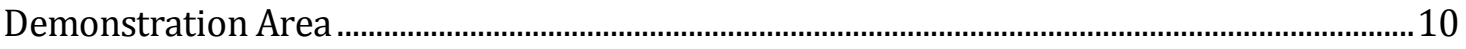

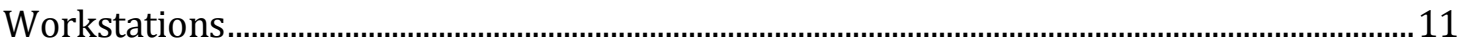

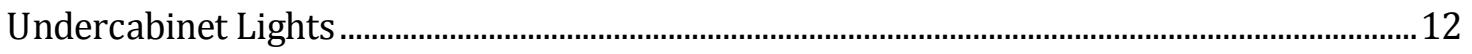

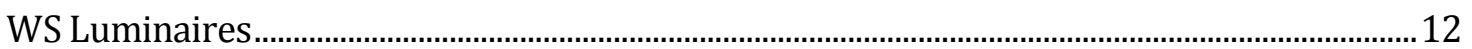

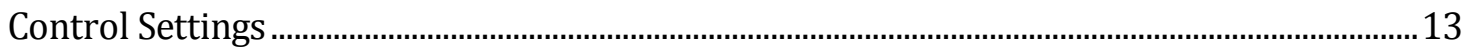

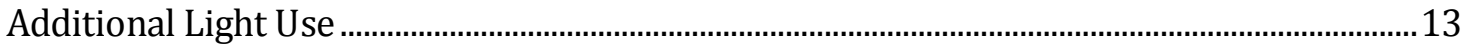

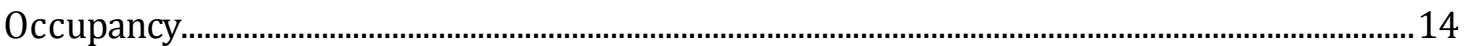

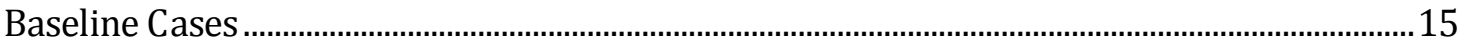

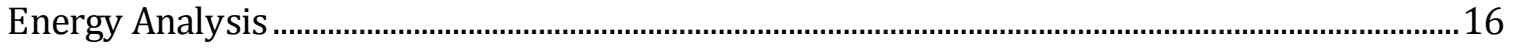

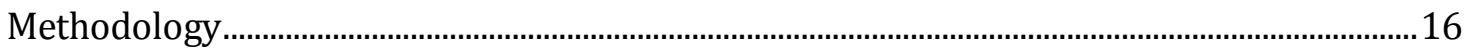

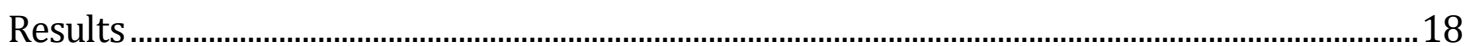

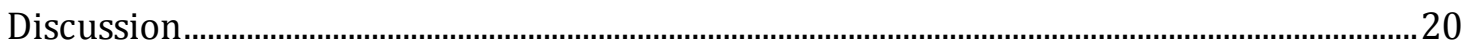

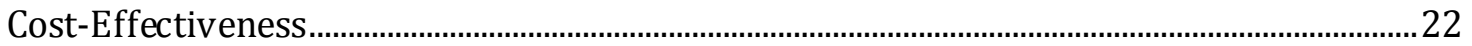

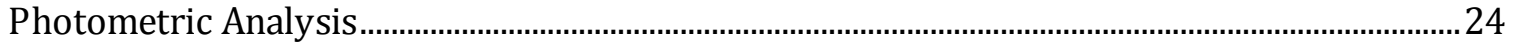

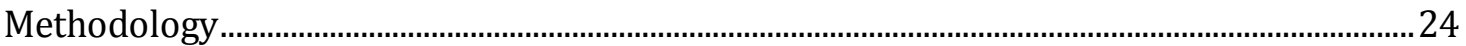

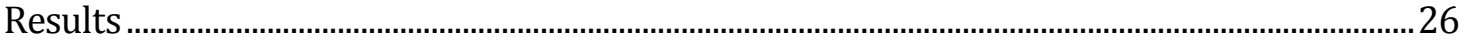

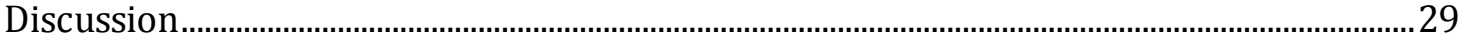

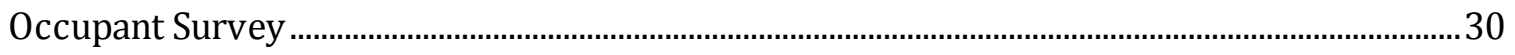

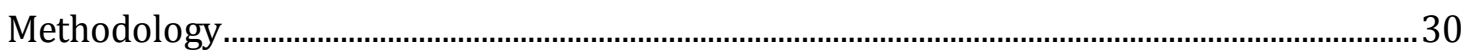

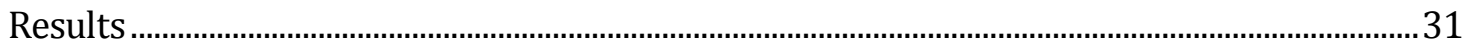

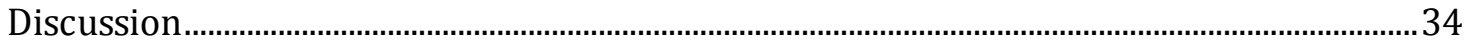

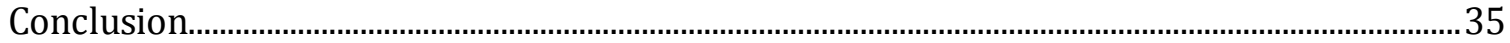

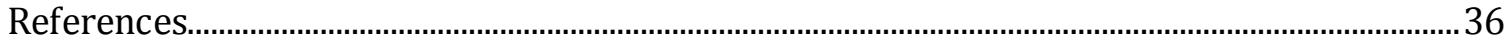

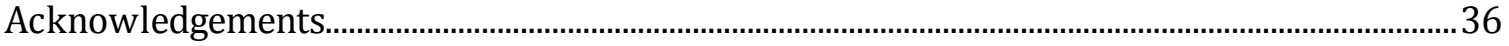

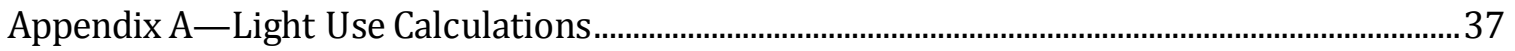

Appendix B-Occupant Survey .....................................................................................................

Appendix C-Occupant Survey Results ............................................................................................. 45 


\section{Executive Summary}

\section{Introduction}

Lighting systems consume about $25 \%$ of the electrical energy used in US commercial buildings [2]. Advanced lighting controls are a practical and economical means to dramatically reduce the energy footprint of commercial building lighting systems, make building electrical systems more responsive to the real-time price of energy, and provide light when and where it is needed. One emerging approach to highly-efficient open-office lighting is a workstation-specific (WS) luminaire system, in which an independently controllable overhead luminaireprovides both ambient and task light for each workstation. WS luminaires have the potential to reduce en ergy use while giving occupants personal control over their lighting conditions. This report documents the energy savings, lighting conditions, and occupant satisfaction documented in a demonstration project with WS lighting in an open office in the General Service Administration's (GSA's) Philip Burton Federal Building in San Francisco.

During a2009 lighting retrofit, pendant-hung WS luminaireswere installed in 86 cubicles in a roughly 8200 square foot open-office area with low levels of daylight. Each WS luminaire provides both upward ambient lighting and downward task lighting and includes an occupancy sensor. A central system controls the luminaires and programsboth task and ambient lights to adjust to individual cubicle occupancy, turning on when someone enters the cubicle and fading off if the cubicle remains unoccupied for a specified timeout. This differs from typical WS lighting, which leaves ambient lights on in unoccupied cubicles during work hours to ensure sufficient room surface brightness; by shutting off ambient lights, the installation studied demonstrates a bold and perhaps extreme approach to WS lighting. Light levels can be set on an individual basis, butas currently implemented occupants only have indirect control over theirworkstation lighting. Occupancy levels are generally fairly low, with peak daily occupancy averaging $63 \%$ over the 32 weekdays studied.

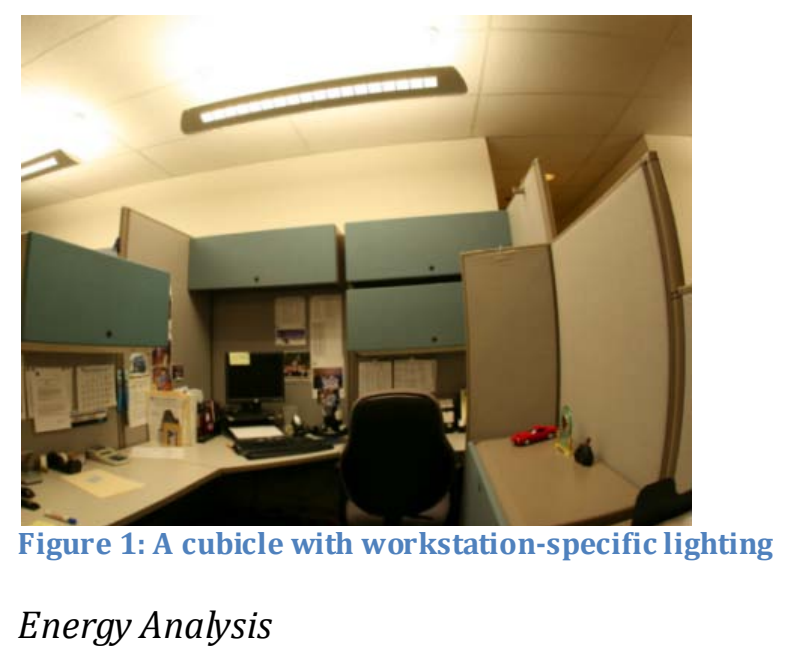

Over the 32 days studied, the installed WS system achieved $40 \%$ daily energy savings compared to "GSA standard", a baseline that conforms to GSA's current retrofit standard(adopted 2005, Facilities Standards for the Public Buildings Service, P100-2005) and isrepresentative of retrofits in the past 5 years. The GSA standard system, installed on 
another floor in the same building, has direct/indirect pendant luminairesin continuous rows, a lighting power density (LPD) of $0.83 \mathrm{~W} / \mathrm{ft}^{2}$, and $\mathrm{ON}-\mathrm{OFF}$ switching at the room level only.Even though the WS system's installed LPD of $1.23 \mathrm{~W} / \mathrm{ft}^{2}$ exceeds that of GSA standard, the WS system's actual LPD remains well below GSAstandard's level throughout the day. The WS system capitalizes on dimming and occupancy patterns to achieve an average daily energy density of $7.92 \mathrm{~W}-\mathrm{h} / \mathrm{ft}^{2} /$ day, compared to $13.25 \mathrm{~W}-\mathrm{h} / \mathrm{ft}^{2} /$ day for GSA standardand $22.5 \mathrm{~W}$-h/ft 2 /day for "GSA base", a lighting retrofit typical of a decade ago (representative of the majority of GSA owned inventory). Energy numbers reflect overhead lighting only and do not include undercabinet or desktop task lighting. This analysis demonstrates that WS lighting can achieve significant energy savings in an open-office environment.

Occupancy patterns, workstation density, timeouts, standby power, and control strategies all affect the energy savings associated with WS lighting and should be addressed during project planning. In particular, installations in low occupancy offices and those that achieve very low standby power will have the most success. Incorporating daylighting and/or personal controls could increase energy savings significantly beyond the levels recorded here.

As installed, the WS retrofithas a simple payback period of 8.6 years based on an existing GSA base system; a GSA standard retrofit has a payback period of 5.5 years.Basing investment in WS luminaires on en ergy alone will therefore be a challenge withoutreductions in costs, increases inenergy savings, or a directive to reduce greenhouse gas emissions.

\section{Photometric Analysis}

In addition to saving energy, the installed WS system generates high er desktop light levels than GSA standard and provides IESNA recommended desktop light levels under real-world conditions. Illuminance levels in WS cubicles at the front of the desksaverage 474 lux and 601 lux at default and full power settings, respectively, and all measurements at default settings exceed 350 lux except where occupants requested lower light levels.GSA standardilluminance levels average 326 lux. This demonstrates that by focusing light in each workstation, a WS system can save energy without compromising lighting conditions for occupants at their desks.

WS lighting typically provides the significant benefit that occupants can adjust light levels on an individual basis and work under their preferred lighting conditions even in a large open office.

\section{Occupant Survey}

A survey found that occupants with WS lighting generally appear more satisfied than occupants with GSA standardlighting. They are more likely to find their lighting comfortable and evenly distributed, less likely to experience glare associated with the lighting system, less likely to want the location and look of their fixtures adjusted, and less likely to want an additional task light. These trend suggest that the WS system successfully provides more desirablelight conditions in the workstations than GSA stan dard does.

Occupants with both systems expressed strong inter est in increased control over their lighting conditions. Though not yet incorporated into this installation, per sonal controls are a natural component of a WS lighting system. Survey responses suggest that the personal control typically associated with WS lighting could provide a major benefit to occupants. 
Several concernsregarding the overall office environment were not directly addressed in the survey, including low corridor light levels, irregularly lit ceilings, and the effect of light switching on adjacent cubicles. These can be ameliorated in future projects by providing additional corridor lighting, dimming rather than turning off ambient lights during work hours, and programming lights to fade more slowly. The first two of these changes will of course increase energy use.

\section{Lessons Learned}

This project revealed a few key lessons for future WS retrofits. First, fixtures should be assembled offsite whenever possible, and modifications in the field should be minimized. Second, occupancy patterns have an important effect on energy savings; relatively lowoccupancy and variable-occupancy offices have the most to gain from WS lighting. Third, standby power contributes significantly to overall energy use. Efforts to reduce standby power and/or strategically shut off power to fixtures at certain times will increase savings. Finally, personal controls should be incorporated whenever possible, both to increase energy savings and to improve occupant comfort and satisfaction.

\section{Conclusion}

This study demonstrates that by focusing light when and where it is needed, WS lighting can achieve large energy savings compared to GSA standard while providing higher workstation light levels and improving occupant satisfaction. Although not yet implemented here, personal taste and controls can be elegantly accommodated in a WS lighting system, allowing occupants to set and adjust light levels as they see fit even in an open-office setting.

The installation discussed here demonstrates one of many possible approaches to WS lighting. Adding personal controls or daylighting, providing additional corridor lighting, and changing the control strategy to make ambient light levels more consistent will affect energy use and occupant satisfaction. Cubicle size, layout, and the specifics of the installed ballasts, sensors, lamps, and fixtures will change the equation as well.

As tested, the WS system needs to achieve lower costs and/or higher energy savings to compete with GSA standard on pur ely economic grounds. Higher energy savings can be achieved by lowering standby losses, providing personal controls, incorporating daylighting, improving commissioning, and reducing timeouts. Projects focused on reducing greenhouse gas emissions could benefit greatly from WS lighting even without these additional savings. Further, occupants' lighting conditions should play a key role in retrofit decisions, and the WS system's ability to simultaneously save energy and create a positive luminous environment in workstations should give it an edge over many uncontrolled alternatives. 


\section{Introduction}

Lighting systems consume about $25 \%$ of the electrical energy used in US commercial buildings [2]. Advanced lighting controls are the most practical and economical means to dramatically reduce the energy footprint of commercial building lighting systems and make building electrical systems more responsive to the real-time price of energy [5]. Controls also provide an opportunity to maximize efficiency while maintaining favorable lightingconditionswhen and where they are needed. Despite these advantages, key interested parties, ranging from building managers to large public and private owners, are unaware of how new control technologies have significantly improved the energy-efficiency of lighting systems. Efficient, highly-controlled lighting for open-plan office spaces has always been a challenge for facility designers. This work describes one emerging solution workstation-specific (WS) luminaires - that offers tremendous potential advantages in terms of energy efficiency and providing luminous conditions that reflect occupant needs in openplan offices.

The General Services Administration (GSA) is responsible for managing a large inventory of diverse Federal buildings totaling 300 million square feet of building stock. Strategically, the GSA has been examining the technical performance and cost-effectiveness of different energy-efficient lighting technologies in their existing buildings as well as in buildings under construction and in the pipeline. Since many of the GSA's office buildings use openplan designs for much of their usable floor space, identifying highly energy-efficient lighting solutions for this type of space has been a high priority for the GSA for several years.

This report describes the results of a retrofit withWSluminaires at the GSA's Philip Burton Federal Building in San Francisco and summarizes the measur ed energy savings, lighting conditions, and occupant responsesthat have been realized to date in this installation.

\section{Workstation-Specific Luminaires}

Workstation-specific (WS) luminaires are designed to provide highly-efficient, customizable lighting for cubicles in open-office areas.

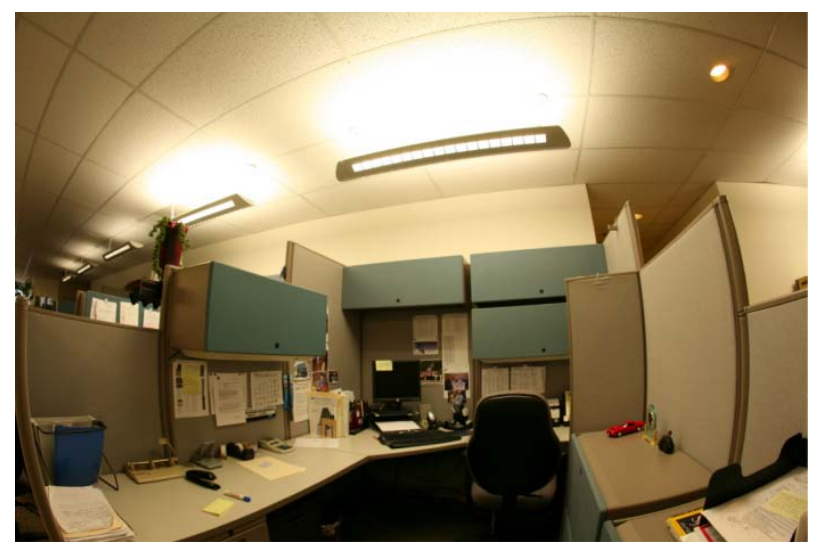

Figure 2: Cubicles lit with workstation-specific luminaires during a pilotstudy at the Philip Burton Federal Building. 
Workstation-specific luminairestypically have the following features:

- One or more independently controllable luminaire[s] per workstation

- Direct/indirect, pendant-mountedluminaires

- Separable control of "ambient" and "task" lighting components: Usually one dimmable lamp provides the ambient(or "uplighting") component, while anothertwo dimmable lamps provide the baffled task(or "downlighting") component.

- Occupancy sensors and/or photocells, typically built directly into the luminaire, as well as all associated control circuitry required to commission and operate the system

- Networked together using a microcontroller that implements a controls communication protocol (typically DALI) to all luminaires

- Use of a computer to run application-specific control software and collect energy data

WS luminaires take advantage of layout and advanced controls to focus light in workstations rather than throughout an open office. The control system and sen sors intelligently control the behavior of both task and ambient components in accordance with operational requirements. Since each lu minaire is in dividually controllable, light levels can be set and adjusted according to individual occupant preferences.

\section{Background}

Several studies have found that occupants prefer directcontrol over their lighting and that people select a wide range of light levels when given this control [1][6][9]. This suggests that WS lighting with personal controls could provide major benefits to open-office occupants. Two recent studies evaluated this possibility. A study of 86 workstations in British Columbia found that a combination of daylighting, occupant sensing, and personal control resulted in close to 70\% energy savings compared to an uncontrolled baseline [4]. A smaller study found that WS luminaires with occupancy sensors and personal controls saved $32 \%$ of daily energy use compared to a baseline [3]. In both studies, uplights remained on throughout the workday to provide ambient light. The choice of baseline will of course have a fundamental effect on percentage savings calculations.

In 2007, the GSA commissioned Lawrence Berkeley National Laboratory (LBNL) to run a small pilot study to identify the energy savings and cost-effectiveness ofWS lighting in a typical GSA building (the Philip Burton F ederal Building). Two types of WS luminaireswith occupancy sensors and photosensorswere selected for testing and installed in 15 seven by nine foot cubicles. Researchers compared the energy, demand and light levels from these two experimental lighting zones to a control zone with an uncontrolled, but low power density,direct/indirect lighting system. As reported in a recent paper, one type of WSluminaire that extinguished downward task lights in unoccupied cubicles used $53 \%$ less energy than the baseline system while providing higher desktop light levels[8].This led to interest in an expanded study of WS luminaires in the same building. 


\section{Current Demonstration}

\section{DEMONSTRATION AREA}

Based on the outcome of the pilot study, GSA elected to build-out a larger demonstration area in which to evaluate a more economical solution using WSluminaires that would better fit GSA's economic criteria and operational requirements. The demonstration took place in an open-office area on the $4^{\text {th }}$ floor of the Philip Burton Federal Building that contains 86 cubicles in three zones. Occupants work for GSA and typically spend most of their time performing typical office tasks, with occasional travel. The building has a deep floor plan, and only the east zone receives significant levels of daylight. For the purposes of the study, daylighting was not incorporated into the WS system as a control strategy.

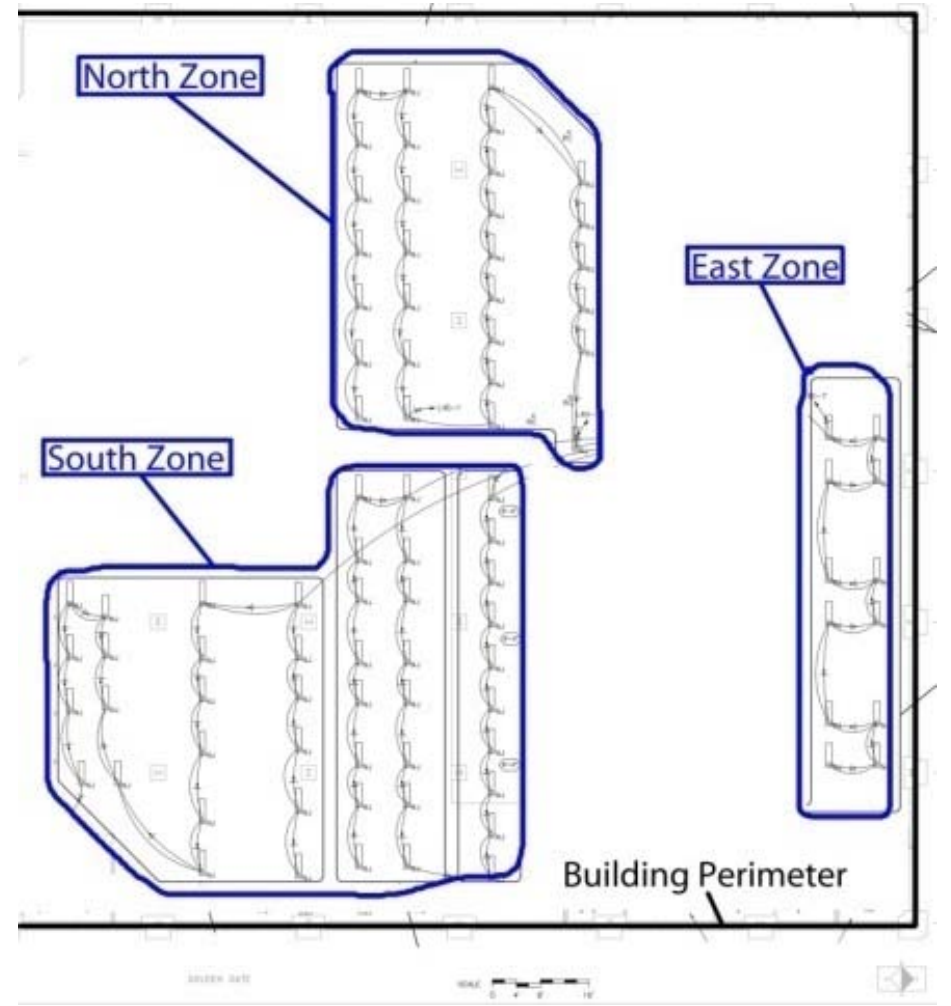

Figure 3: The location of the 86 workstation-specific luminaires used in the demonstration area at the Philip Burton Federal Building.

Floor areas include both the cubicles and corridors insideeach zone, with the exception of two short corridors and an open aisle area in the south zoneand a small section of corridor in the north zone which are lit by recessed downlights with compact fluorescent lamps (CFLs) and were therefore excluded from area takeoffs. Corridors along the outside edges of the zones were included if they did not contain other luminaires and excluded if they did. Six long corridors in the north and south zones each containa single recessed downlight with a CFL. These luminaires were not taken into account; their energy use was not measured and the floor area was not adjusted to account for their presence. Emergency lighting is provided entir ely by selected recessed downlights, including perimeter fixtures 
as well as some of the fixtures mentioned above; energy numbers in this report exclude emergency lighting.

\begin{tabular}{|l|l|l|l|}
\hline Zone & $\begin{array}{l}\text { Calculated floor area } \\
\left(\mathbf{f t}^{2}\right)\end{array}$ & $\begin{array}{l}\text { Number of } \\
\text { workstations }\end{array}$ & $\begin{array}{l}\text { Average } \mathrm{ft}^{2} \text { per } \\
\text { workstation }\end{array}$ \\
\hline South & 4,260 & 45 & 95 \\
\hline North & 2,780 & 29 & 96 \\
\hline East & 1,150 & 12 & 96 \\
\hline Total & 8,200 & 86 & 95 \\
\hline
\end{tabular}

Table 1: Floor area takeoffs for each zone and for the entiredemonstration area. Floor areas do not sum exactly due to rounding.

\section{WORKSTATIONS}

Typical workstations in the study area are seven by nine feet in plan and have four sections of desk surface, as shown in Figure 4. Several large cabinets line the walls of each cubicle in varying configurations. Partitions are 81 " high between rows of cubicles. In the four rows in the southwest, partitions remain 81" tall on all sides of each cubicle. In the rest of the study area, partition s between cubicles split into either three sections 81", 66", and 54" tall or two sections 81" and 54" tall. Partitions along cubicles' entrance walls are 54" throughout, except in the southwest.Descriptions and reflectances of relevant surface materials are recorded in Table 2.

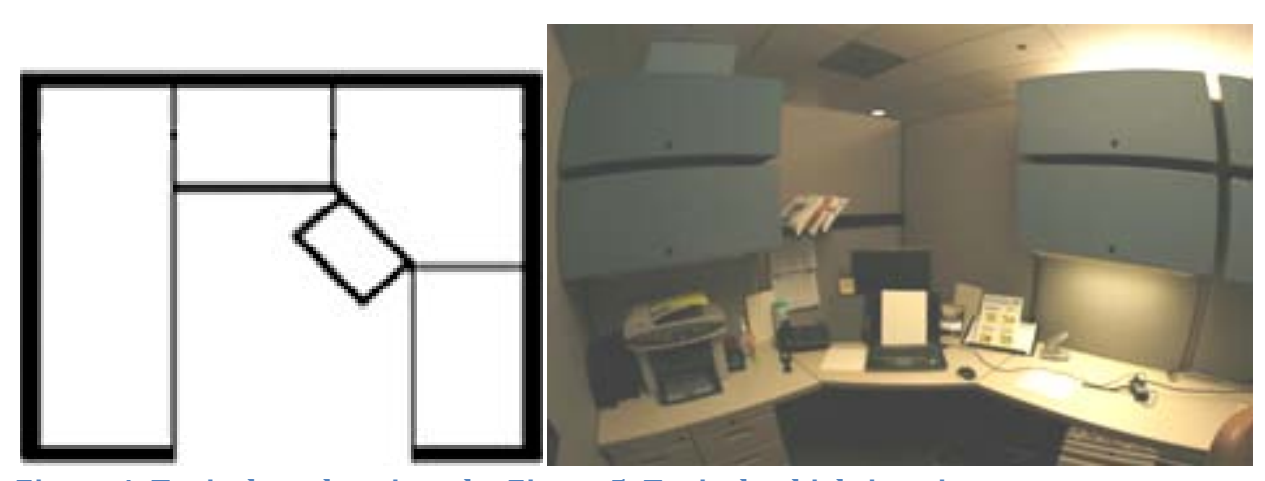

Figure 4: Typical workstation planFigure 5: Typical cubicle interior

\begin{tabular}{|l|l|l|r|}
\hline Surface & Material & Color & Reflectance \\
\hline Desk & Plastic laminate & Light gray & 0.52 \\
\hline Cabinet front face & Fabric & Turquoise & 0.18 \\
\hline Partitions & Fabric & Medium gray & 0.31 \\
\hline Ceiling & Acoustic tile & Off-white with cavities & 0.79 \\
\hline Floor & Carpet & Dark gray, mottled & 0.04 \\
\hline
\end{tabular}

Table 2: Surface materials and reflectances in the demonstration area 


\section{UNDERCABINET LIGHTS}

Energy numbers throughout this report refer to overhead lighting only and exclude undercabinet and desktoptask lights for both the WS and baseline systems. Comparisons are made on the assumption that additional task light use would remain roughly constant under all three systems.

Each workstation containsfrom zero to threebuilt-in undercabinetlamps, typically 2-foot, 20 watt lamps or, in a minority of cases, 4-foot, 40 watt lamps. The average installed power per workstation from undercabinet lights is about 40 watts, and the maximum is 60 watts. A few occupants supplemented this lighting with small table lamps. Energy use by undercabinet lights and table lamps could not be measured due to outdated plug load circuit diagrams.An afternoon survey of 66 WS cubicles in the north and south zones found 26 occupants, 13 undercabin et lights turned on, and 2 standing desk lamps turned on. These general proportions were confirmed informally at several points during the study period. Light use varies widely between occupants, with several lights left off in unoccupied cubicles, some occupants using multiple undercabinet lights, and many occupants using only overhead lighting.

In order to conduct this analysis, it was assumed that undercabinet and desk lamp use would remain roughly constant in the baseline and WS cases and so would not affect overall energy use comparisons. Thisapproach does not take into account modified undercabinet light use patterns that may result as occupants react to different overhead light conditions. Since occupants with lower light levels are expected to use additional task lights more frequently, this approximation is conservative at least with respect to GSA standard, which provides lower light levels than the WS system, as discussed later.

\section{WS LUMINAIRES}

A parabolic, direct/indirectluminaireis installed at each workstation. Each luminaire has three 32 watt T-8 lamps (color temperature $4100 \mathrm{~K}$ ), two controlled by a DALI-capable dimmable ballast for downward task lighting and one controlled by a separatedimmable ballast for upward ambient lighting. An occupancy sensor is connected to the downlighting ballast via a powerpack. Fixtures also include built-in photosensors, which were not activated during this study. A DALI-capable lighting controller (Lumenergi Lighting Measurement Control System (LMCS)) records the power level commanded to each ballast at 2 minute intervals.

The installation faced logistical challenges that could be avoided in future projects. The initially installed fixtures had $0-10 \mathrm{~V}$ rather than DALI capabilities; the retrofit to DALI occurred onsite. The maintenance personnel who changed wiring in the field often had little experience with this type of retrofit. As a result, the project faced numerous performance issues and callbacks due to wiring mistakes. It is strongly recommended that future projects treat fixture assembly as a manufacturing process rather than an installation process and that fixtures be assembled offsite whenever possible. 


\section{CONTROL SETTINGS}

Out of a wide range of possible approaches, a boldand perhaps extreme occupancy-based control strategy was selected for this study: both downlights and uplights are programmed to switch on and off according to individual cubicle occupancy as determined by the fixtureintegrated occupant sensor. Lights turn on when someone enters the cubicle, and timeouts begin when the cubicle becomes unoccupied. If it remains unoccupied during the scheduled timeouts, the lights fade off.Lights dim gradually when switching to lower power levels or turning off. Previous studies have typically left uplights on in unoccupied cubicles during work hours[3][4][8].

Light levels are set through "input power" levels that correspond to a DALI number that the control system commands to a ballast. "Input power" levels do not correspond closely to actual power levels, as will be discussed later. All the ballasts were initially set to default settings, recorded in Table 3,from which light levels and timeouts could be adjusted based on occupant requests. Several months after the installation took place, approximately $80 \%$ of the workstations still used default settings. This probably occurred mostly because occupants had only indirect control over their lighting conditions, as discussed below.Adjustments generallyincreased or decreased the "on power" levelor increased timeouts to prevent lights from shutting off in occupied cubicles.

\begin{tabular}{|l|l|l|}
\hline Setting & 2 lamp ballasts (downlighting) & 1 lamp ballasts (uplighting) \\
\hline On "input power" & $75 \%$ & $50 \%$ \\
\hline Timeout at on power & 20 minutes & 20 minutes \\
\hline Preliminary “input power" & $30 \%$ & $30 \%$ \\
\hline Timeout at preliminary power & 10 minutes & 10 minutes \\
\hline
\end{tabular}

Table 3: Default "input power" and timeout settings for the WS luminaires. After a workstation becomes unoccupied, the timeout at on power is followed by gradual dimming and a timeout at preliminary power. After the second timeout, the lights fade to turn off. As discussed later, "input power" does not correspond well to actual power levels.

As currently operated, lights are controlled entirely by the central control system, with no direct occupant adjustments or overrides available. To adjust light levels and timeouts, occupants have to request changes, which are implemented by a building occupant who has access to the control room and knows how to use the control interface. There are no wall switches to override the control system and turn lights off, and occupants cannot adjust light levels manually.GSAintends to set up a web-based system that will allow occupants to control their light settings directly and plans to incorporate this type of control system into future projects.

\section{ADDITIONAL LIGHT USE}

Two factors increased light use in the WS installation beyond that defined by occupancy patterns and the control settings defined above. Eliminating these factors would have decreased energy use somewhat. As discussed below, calculations suggest that these potential savings would have been well under $10 \%$ of daily energy use. 
First, the uplights in 11 workstations were set to turn on to $75 \%$ "input power" from 7 to 10 p.m. every weeknight, followed by their usual timeouts. This schedule was designed to provide lighting for custodians and other people moving through the building after hours. Averaged over the entire floor area,the most this schedul ed setting could have contributed to energy use is approximately 0.15 watt-hours per square foot per day,or less than $2 \%$ of the total. The actual effect was undoubtedly smaller since in many cases some of the lights would have stayed on for at least some of the scheduled time due to cubicle occupancy. Calculations are included in Appendix A.

Second, three luminaires had significant performance issues that could be identified from the data sets and that resulted in lamps staying on far longer than intended. In two of these luminaires, all three lamps stayed on for over 20 hours on 16 and 22 of the 32 days studied, respectively. Both workstations had several days in which lights stayed on for 24 hours. In a third luminaire, only the uplight malfunctioned, staying on for over 20 hours on 23 of the 32 days studied. When averaged over the entire floor plan, aluminaire that stayed on at default settings for an extra 12 hours per day would contribute an additional 0.13 watthours per square foot per day, less than $2 \%$ of the average weekdayenergy use. Thus, the effect of these three malfunctioning fixtures is expected to be below $5 \%$. Calculations are included in Appendix A.

Occupancy sensors that triggered in unoccupied cubicles contributed to increasing energy use as well, though this effect could not be quantified since false triggering was not identifiable in the data. Sensor s have shields to prevent false triggering, but several shields were missing for the duration of the project, and the corresponding sensors sometimestur ned the lights on when someone walked by in the corridor.

\section{OCCUPANCY}

Because an occupancy sensor was associated with each luminaire and occupants could not override the central control system, high-resolution occupancy statistics were easily accessible. The control system collected each ballast's status every two minutes. After timeouts were subtracted out, this translated into 2 minute interval readings of the occupancy status of each workstation. An analysis of occupancy levels in 82 workstations over the 32 workdays studiedresulted in the distribution shown inFigure 6 (four workstations were eliminated from analysis because they did not provide sufficient occupancy information).

These results are based on the assumption that the sensors worked correctly. False sensor triggering results in overestimated occupancy levels, while sensors that falsely record an occupant's absence have the opposite effect. Both errors occurred during the project, according to observation and occupant feedback. Further, since these results are based on power levels set by the control system rather than a direct record of each sensor's status, they can only recognize unoccupied periods of time that last long enough for the lights to drop to preliminary power levels (typically 20 minutes), which encourages a slight overestimation of occupancy levels. 


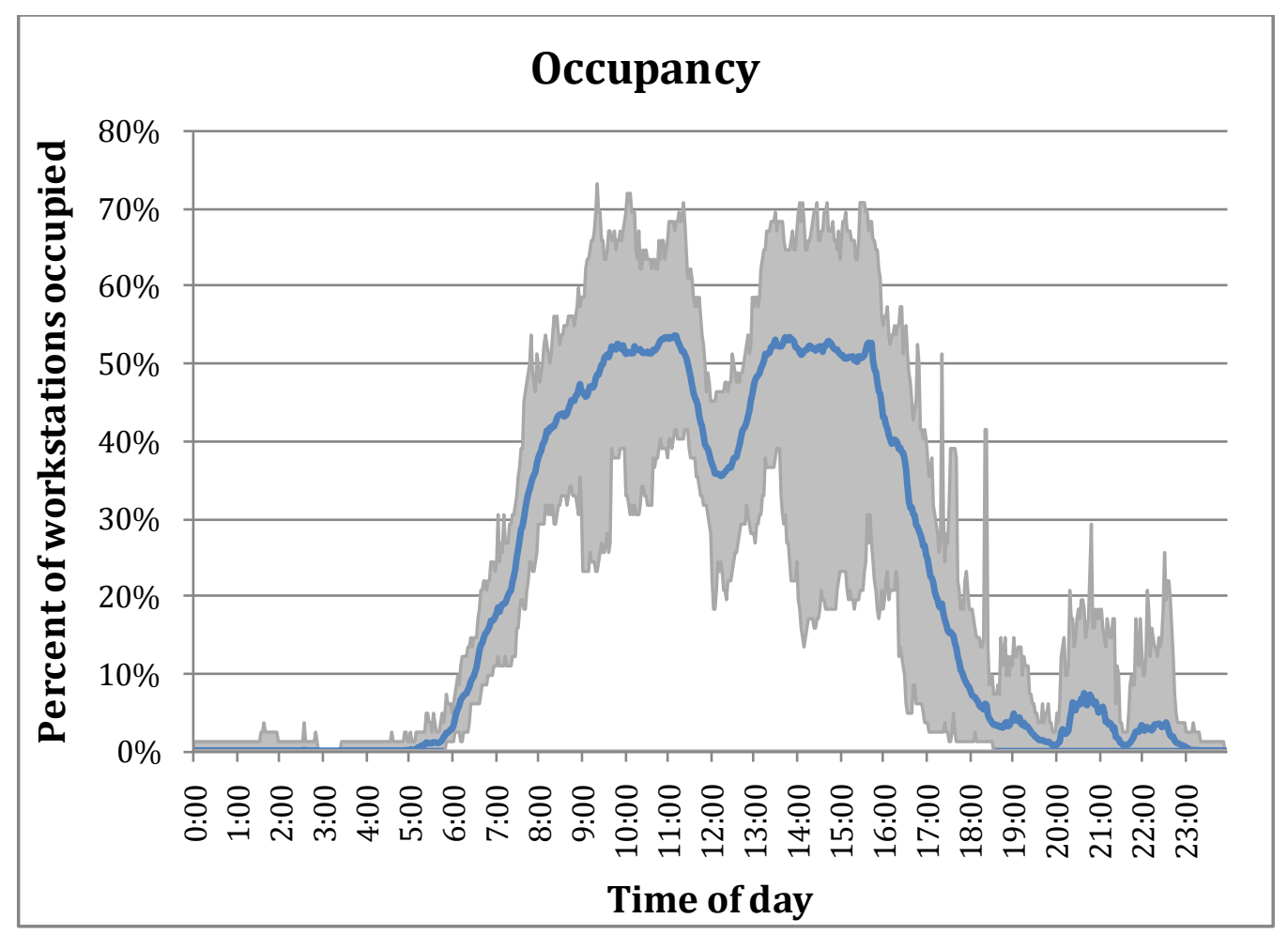

Figure 6: Occupancy statistics from 82 workstations over 32 weekdays. The blue line gives the mean occupancy percentage at two minute intervals, and the shaded areas extend to the minimum and maximum occupancy at each time. Average occupancy peaks below 55\%, and the average peak daily occupancy is about $63 \%$. Four workstations were eliminated from the occupancy analysis because they did not provide adequate information: One light was set to never turn on, two stayed on almost continuously, and one had a very long timeout that prevented meaningful data acquisition.

Occupancy levels are generally fairly low. Average occupancy peaks below 55\%, and peak daily occupancy averages roughly 63\%. Average daily occupancy is just over five hours per cubicle, and twenty-two of the 82 workstations qualify as consistently low occupancy, as defined by having less than three hours of occupied time on at least half of the days studied. There is also a large range between the highest and lowest occupancy levels at each time; daily occupancy patterns in the study area vary significantly.

Relatively low and highly variable occupancy levels are an ideal environment for workstation-specific luminaires, which capitalize on individual absences.

\section{BASELINE CASES}

Two baseline cases are used for this analysis, each of which is representative of typical GSA installations. Both baseline systems have ON-OFF switching control systems at the room level only, lights that are left on throughout the workday, and luminaires that draw no power when turned off. Occupants with baseline lighting do not have control over their overhead lighting. Energy use for the baseline cases is calculated rather than measured based on system characteristics and assumptions about use patterns.

The first baseline case, 'GSA stan dard', conforms to GSA's current standard (adopted 2005, Facilities Standards for the Public Buildings Service, P100-2005). It is typical of retrofits in the past five years and is currently installed in open-office areas on another floor of the 
building. Pendant-mounted, direct/indirectluminaires with a one-lamp cross section are installed in continuous rows, with 8-foot spacing between rows. Luminaires have 32 watt T-8 lamps and GE Ultramax normal ballasts, with an input power of 53 watts per 8-foot length of luminaire. Lights are assumed to stay on for 16 hours each day. These long lighting hours were verified by direct circuit monitoring during the 2007 pilot study described earlier. This results in a lighting power density (LPD) of 0.83 watts per square foot and a daily energy use of 13.25 watt-hours per square foot per day.

Although energy use in the GSA standard installation was calculated rather than measured, open-office areas with theGSA standardsystem were evaluated alongside WS areas during photometric analysis and in the occupant survey. Cubicle layout, daylight levels, undercabinet lights, and surface materials in the GSA standard area are for the most part identical to those in the WS study area.Both GSA standard and WS occupants work for GSA, and the two groups perform similar tasks.

The second baseline, called GSA base, is typical of GSA retrofits a decade ago and representative of the majority of GSA-owned inventory. Recessed, 2x4, 18-cell parabolic louver trofferluminaires with three T-8 lamps each are tandem wired in pairs, with two 2lamp ballasts in one fixture and a single 2-lamp ballast in the other. Each fixture draws 90 watts, and fixtures are spaced 8 feet on center in both directions. Lights are assumed to stay on for 16 hours each day. LPD is a high 1.41 watts per square foot, and the system consumes 22.5 watt-hours per square foot per day.

Relevant information about both baseline cases is presented in Table 4.

\begin{tabular}{|c|c|c|c|c|c|}
\hline Baseline case & $\begin{array}{l}\text { Fixture } \\
\text { power }(W)\end{array}$ & $\begin{array}{l}\text { Floor area } \\
\text { per fixture } \\
\left(\mathrm{ft}^{2}\right)\end{array}$ & $\begin{array}{l}\text { Lighting power } \\
\text { density }\left(\mathrm{W} / \mathrm{ft}^{2}\right)\end{array}$ & $\begin{array}{l}\text { Hours per } \\
\text { day (h/day) }\end{array}$ & $\begin{array}{l}\text { Daily energy } \\
\text { density (W- } \\
\text { h/ft } / \text { day) }\end{array}$ \\
\hline GSA standard & 53 & 64 & 0.83 & 16 & 13.25 \\
\hline GSA base & 90 & 64 & 1.41 & 16 & 22.5 \\
\hline
\end{tabular}

Table 4: Baseline case characteristics

As discuss ed earlier, energy use for the baseline and WS systems includes overhead lighting only, and excludes contributions from undercabinet task lights.Calculations also exclude the energy associated with emergency lighting.

\section{Energy Analysis}

\section{METHODOLOGY}

Every two minutes, the central control systemrecords each ballast's status in the form of a chosen power setting - called "input power" although it does not correlate well with actual power levels - that corresponds to a DALI number that the system command s to the ballast. The control system then uses a lookup table to convert the ballast command into the estimated power draw of the ballast.

In order to ensure that the lookup table was correct, bench-top measurements were performed at Lawrence Berkeley National Laboratories (LBNL) on the installed fixture 
configuration of 2 ballasts, 3 lamps,an occupancy sensor, anda power pack. To create the lookup table, power was measured at 10\% "input power" settings with the one and two lamp ballasts activated one at a time. Power associated with the occupancy sensor and power pack was split between the ballasts. This means that estimated total power is the sum of individual ballast power levels from the lookup table. The measurements used in the system's lookup table are included below in Table 5. Intermediate "input power" settings were linearly extrapolated between measured values. Note that actual power percentages differ significantly from "input power" percentages, especially at lower levels. This means that power levels selected in the control system do not correlate well with real power, but it does not affect data analysis, which is based on the measured values.

\begin{tabular}{|r|r|r|r|r|r|}
\hline \multirow{2}{*}{$\begin{array}{c}\text { "Input } \\
\text { power" }\end{array}$} & \multirow{2}{*}{$\begin{array}{c}\text { DALI } \\
\text { (\%) }\end{array}$} & \multicolumn{2}{|c|}{ 1-lamp ballast } & \multicolumn{2}{|c|}{ 2-lamp ballast } \\
\cline { 3 - 6 } & number & Power (W) & $\begin{array}{l}\text { Percentage of } \\
\text { full power }\end{array}$ & \multicolumn{1}{c|}{$\begin{array}{l}\text { Percentage of } \\
\text { full power }\end{array}$} \\
\hline 0 & 0 & 2.25 & $5 \%$ & 2.25 & $3 \%$ \\
\hline 10 & 168 & 13.75 & $33 \%$ & 23.40 & $31 \%$ \\
\hline 20 & 195 & 18.00 & $43 \%$ & 31.95 & $42 \%$ \\
\hline 30 & 210 & 21.80 & $52 \%$ & 39.05 & $52 \%$ \\
\hline 40 & 220 & 25.15 & $60 \%$ & 44.45 & $59 \%$ \\
\hline 50 & 229 & 28.50 & $68 \%$ & 50.50 & $67 \%$ \\
\hline 60 & 235 & 31.10 & $74 \%$ & 55.25 & $73 \%$ \\
\hline 70 & 241 & 33.65 & $80 \%$ & 60.65 & $80 \%$ \\
\hline 80 & 246 & 36.70 & $87 \%$ & 66.45 & $94 \%$ \\
\hline 90 & 250 & 39.35 & $94 \%$ & 71.10 & $100 \%$ \\
\hline 100 & 254 & 42.05 & $100 \%$ & 75.55 & \\
\hline
\end{tabular}

Table 5: Correspondence between "input power", DALI number, and measured power for the one and two lamp ballasts. Input power is recorded in the data acquisition system, which then uses a lookup table to translate in to measured power estimates. The total installed power is 118 watts per workstation, the default (1-lamp ballast at $50 \%$ and 2 -lamp ballast at $75 \%$ ) is 92 watts per workstation, and the standby is 4.5 watts per workstation. These translate into LPDs of $1.23 \mathrm{~W} / \mathrm{ft}^{2}, 0.97 \mathrm{~W} / \mathrm{ft}^{2}$, and $0.05 \mathrm{~W} / \mathrm{ft}^{2}$, respectively.

After eliminating bad data, incomplete records, a multi-week gap in data acquisition, and holidays, 32 complete workdays - 4 in August,11 in September, 6 in December, and 11 in January - made up the final data set. For each day, estimated power was summed over all 86 workstations at two minute intervals.

For several periods of time during and after the study period, the power estimates obtained from the control system records were compared to power measurements made with a Power Site power analyzer, Model PS-3000on a circuit containing the 29 WSluminaires in the north zone. During the study, the direct measurements exceeded the control system's predictions by a roughly constant several watts per workstation. Repair work on malfunctioning devices was conducted during the weeks following the study, and the gap between the two data sets dropped during this period. The most recent day of coincident data had an average gap of 1.4 watts per workstation, an error of just over $4 \%$ of daily energy use. Further, it was confirmed that recorded power levels when all lamps were verifiably off matched expected power levels.

While definitively verifying power estimates with measured data is highly desirable, the narrowing gap between the data sets suggests that during the study period ballasts did not 
always behave as recorded in the control system. It is hypothesized that certain lamps stayed on at low levels even when the system recorded a $0 \%$ "input power" setting. There are several ways that this could have occurred, though a systematic mechanism has not been established. Based on the mo st recent data and on the laboratory power measurements, we are confident that if the system had been performing as intended, energy use would have matched our predicted values to within 5\%. This study can therefore be seen as anextrapolation from recorded ballast commands to the power levels that would have been associated with those commands, had they been carried out correctly.

\section{RESULTS}

The average LPD from the control system's recordsover 32 weekdays is presented below in Figure 7. Even though the total installed LPDin the open office area is 1.23 watts per square foot and the power density with all the lights turned on to defined settings is 0.94 watts per square foot, the averageLPDpeaks atapproximately 0.66 watts per square foot, and for most of the day, power levels are much lower.The average LPD during working hours (6am-6pm) is just 0.52 watts per square foot. These results demonstrate the importance of using actual LPD rather than installed LPD to evaluate highly-controlled lighting. They also highlight the savings associated with dimmable ballasts and finely targeted controls in an open office with low occupancy levels. The majority of ballasts never go to full power, and the lights in every workstation are never on simultaneously. The finely-tuned system takes great advantage of low and fluctuating occupancy levels in a way that a coarser system-with one occupancy sensor for each cluster of workstations, for example-could not.

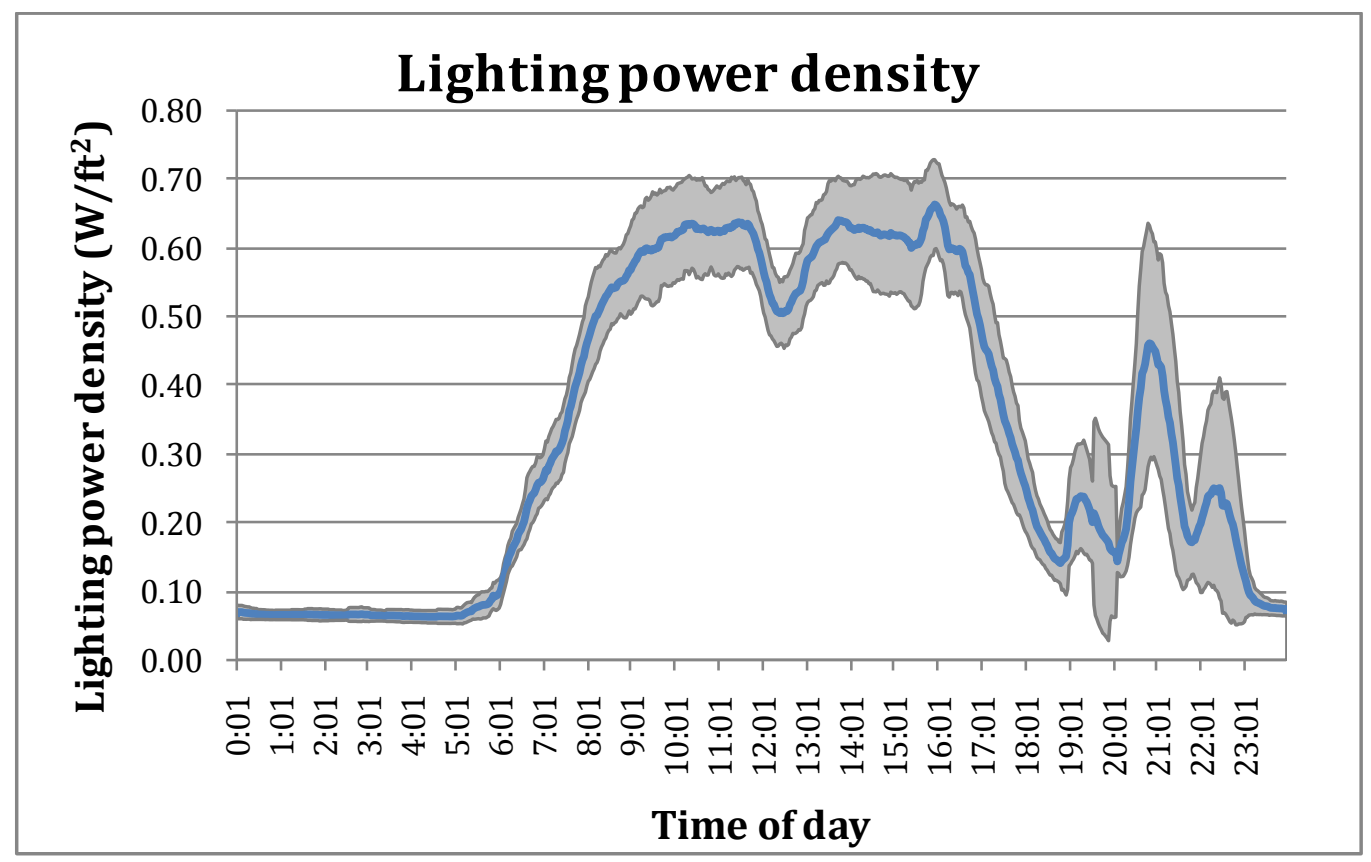

Figure 7: Average LPD in watts per square foot over the 32 days studied. The blue line gives the mean, and the gray shaded areas extend one standard deviation in each direction. Even though the installed LPD is $1.23 \mathrm{~W} / \mathrm{ft}^{2}$ and the default is $0.97 \mathrm{~W} / \mathrm{ft}^{2}$, average LPDpeaks at just over $0.66 \mathrm{~W} / \mathrm{ft}^{2}$, and for most of the time is much lower. Peak daily LPD averages $0.72 \mathrm{~W} / \mathrm{ft}^{2}$. Spikes in the evening largely reflect custodial and security rounds, during which very short periods of occupancy turn lights on for 30 minute timeouts. 
Daily energy usage was calculated from the data sets and is presented in Figure 8 alongside that ofGSA standard. The average lighting energy density over the 32 weekdays studied is 7.92 watt-hours per square foot per day. This corresponds to $40 \%$ savings compared to the GSA standardenergy density of 13.25 watt-hours per square foot per day.

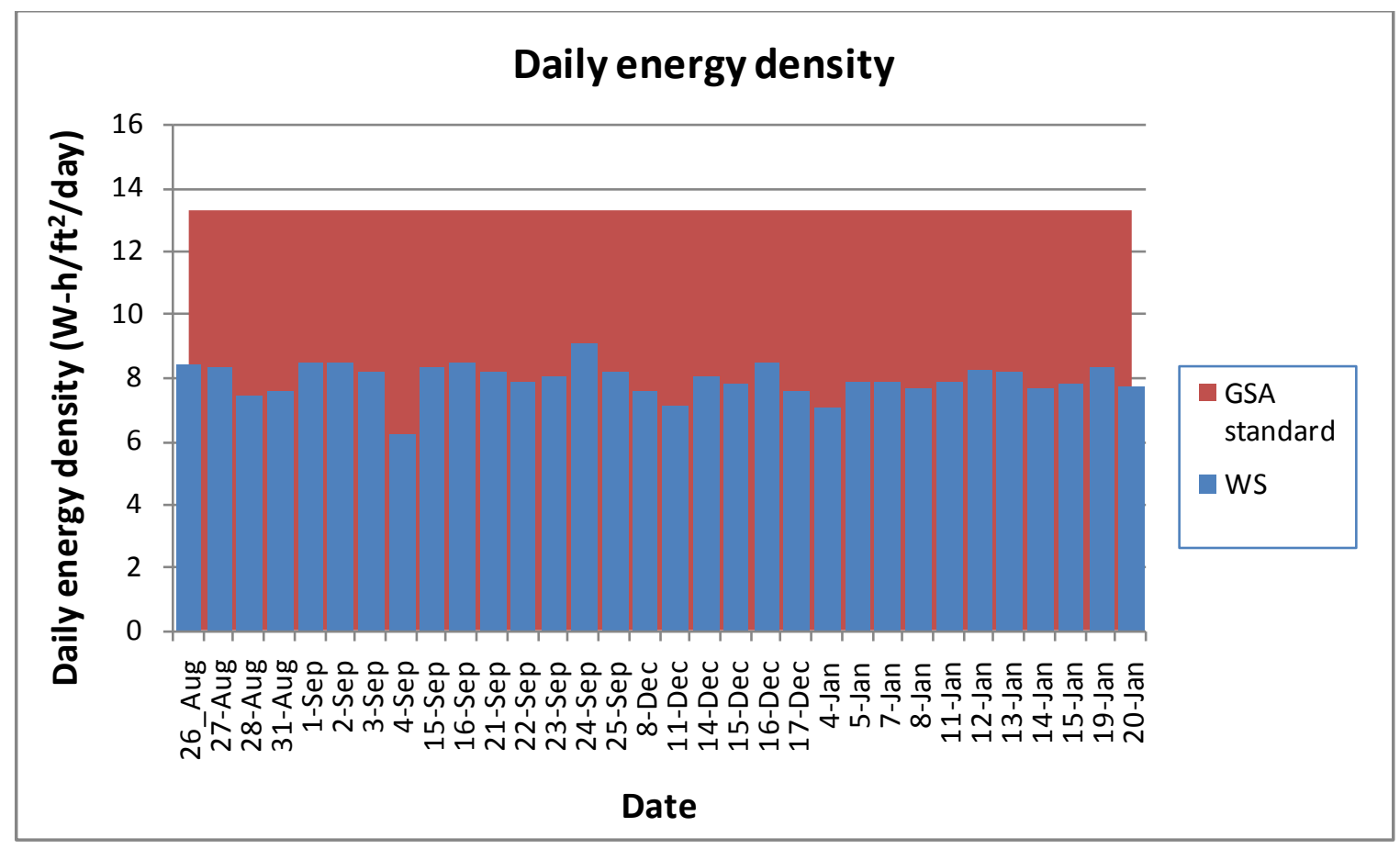

Figure 8: Daily energy density in watt-hours per square foot per day for the 32 weekdays studied. The daily energy density of the GSA standard case is shown in red.

Average daily and annual energy consumption and relative savings are presented below inTable 6,Table 7, and Figure 9. To calculate annual energy use, the office was assumed to be totally unoccupied on weekends. Weekend occupancy during the test period generally remained extremely low, so this assumption does not differ greatly from reality. For the baseline cases, this means the weekend power remains at zero. For the installed system, all lights are assumed to remain at standby power over the weekends. Since the installed luminairesdraw power when they are turned off, the system will save a lower percentage of total energy annually than daily. The assumption that lights will remain off throughout the weekend is a lower bound in terms of total energy use but is conservative with respect to comparison with the baseline cases. As discussed earlier, energy numbers reflect overhead light use only.

\begin{tabular}{|l|r|r|r|}
\hline Case & $\begin{array}{l}\text { Average daily energy } \\
\text { density (W-h/ft }{ }^{2} \text { /day) }\end{array}$ & $\begin{array}{l}\text { Percent savings } \\
\text { from GSA standard }\end{array}$ & $\begin{array}{l}\text { Percent savings } \\
\text { from GSA base }\end{array}$ \\
\hline WS luminaires & 7.92 & $40 \%$ & $65 \%$ \\
\hline GSA standard & 13.25 & $0 \%$ & $41 \%$ \\
\hline GSA base & 22.5 & $\mathrm{~N} / \mathrm{A}$ & $0 \%$ \\
\hline
\end{tabular}

Table 6: Daily energy density and percent savings 


\begin{tabular}{|l|r|r|r|}
\hline Case & $\begin{array}{l}\text { Average annual energy } \\
\text { density (kWh/ft } \mathbf{~} \text { (year) }\end{array}$ & $\begin{array}{l}\text { Percent savings } \\
\text { from GSA standard }\end{array}$ & $\begin{array}{l}\text { Percent savings } \\
\text { from GSA base }\end{array}$ \\
\hline WS luminaires & 2.18 & $37 \%$ & $63 \%$ \\
\hline GSA standard & 3.45 & $0 \%$ & $41 \%$ \\
\hline GSA base & 5.85 & $\mathrm{~N} / \mathrm{A}$ & $0 \%$ \\
\hline
\end{tabular}

Table 7: Estimated annual energy intensity and percent savings

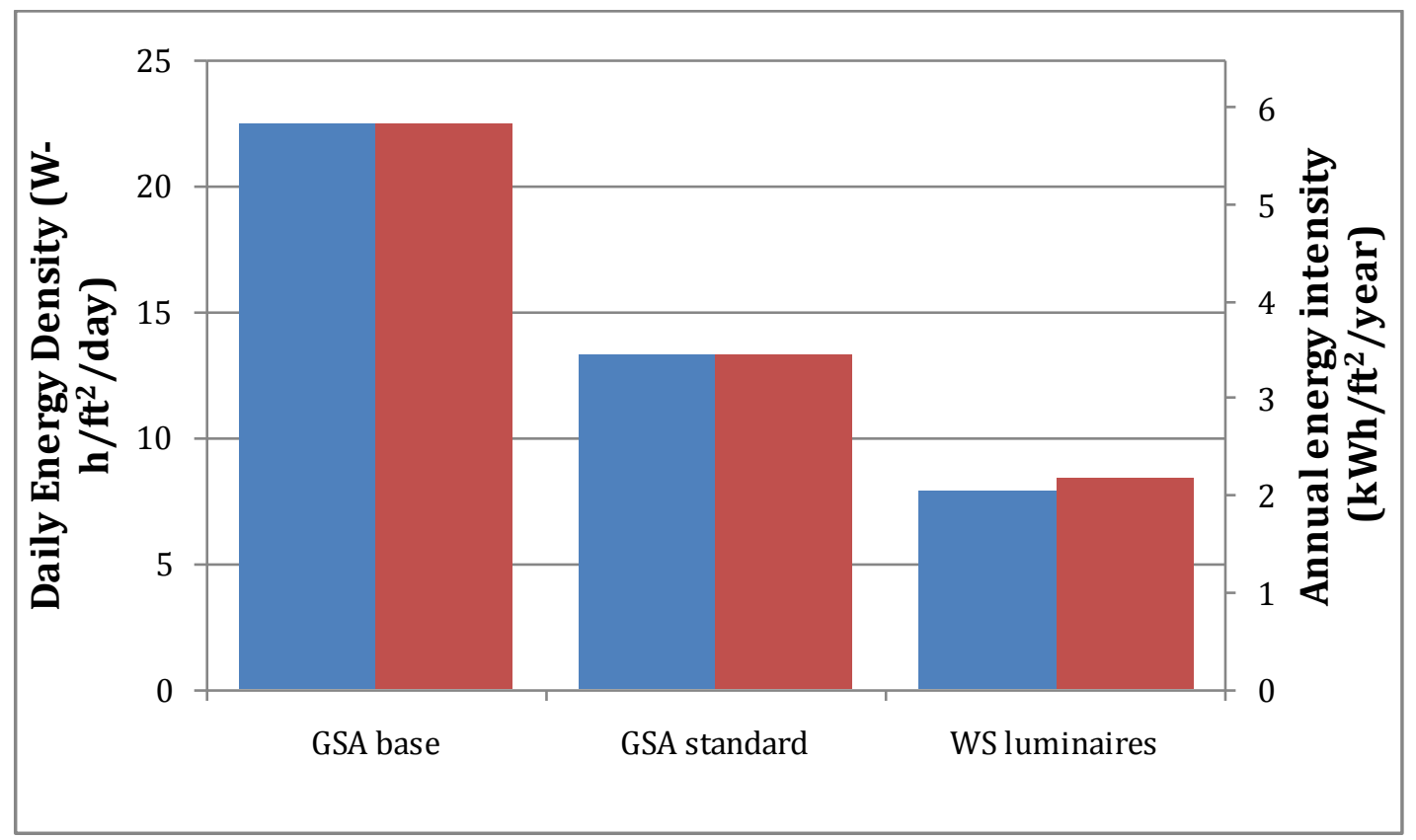

Figure 9: Daily and annual energy use for all three cases. The left bar gives the daily value (plotted on the left axis), and the right bar gives the annual value (plotted on the right axis).

\section{DISCUSSION}

This study demonstrates that highly-controlledlighting in anopen-office environment can achieve large energy savings compared to a low power density, uncontrolled alternative. Even though the WS system had a much higher installed LPD than GSA standard, it took advantage of individual occupancy patterns and achieved $40 \%$ daily energy savings. Savings arose both from dimming lights and from turning off lights in unoccupied cubicles.

Workstation density directly correlates with installed LPD for a WS lighting system. Advanced controls then reduce the actual LPD compared to the installed value.This study calls attention to a handful of key factors that affect the relative success of a WS lighting system given a particular install ed LPD.

Occupancy patterns will have a significant effect on the energy savings associated with WS lighting in an open office. Lower occupancy and more uneven occupancy (varied schedules both between days and between occupants) will increase the benefits of a finely-tuned system like the one studied. At one theoretical extreme, all occupants come to work every day, arrive at the same time, and leave at the same time. In this case, the benefits of individual workstation controls compared to a single wall switch that controls all of the lighting would be eliminated, and the WS system would result in energy losses due to 
increased standby power. At the other extreme, only one occupant at a time visits the space, but the space is never unoccupied; the benefits of a WS system in this case would be tremendous. The closer the real officeis to the second option, the better WS lighting will fare. This study demonstrated large savings for an office with average peak daily occupancy close to $63 \%$. It is strongly recommended that decision-makers study occupancy patterns when deciding if WS lighting is the best approach to a given office environment.

Workstation-specific lighting takes advantage of individual occupant departures, which often occur several times throughout the day for a given workstation. This makes the length and power level oftimeouts important. Over the days studied, an average $31 \%$ of the time the lights spentturned on occurredwhen cubicles were unoccupied. For several underoccupied cubicles, very short periods of occupancy repeatedly triggered30 minute timeouts, which accounted for the vast majority of illuminated time in those cubicles. Further, the large energy density spike each day around 9pm (see Figure 7)occurs because a custodian enters each cubicle very briefly, triggering a 30 minute timeout each time. Long timeouts also increase the wasted energy associated with false occupancy sensor triggering. This suggests that significant savings could be achieved with shorter timeouts and/or lower power levels during timeouts. It also suggests that an alternate control setting with much shorter timeouts could be applied at night and in consistently under-occupied cubicles.

The factors that make WS lighting successful also increase the importance of standby power. Since luminaires spend a large percentage of time turned off, even low standby power will have a significant impact on energy use. Further, to implement WS lighting, each cubicle needs its own occupancy sensor, which typically increases power levels and means that each fixture must draw power for the sensor even when the lights are turned off. In this installation, a standby power of 4.5 watts per cubicle contributedalmost $10 \%$ oftotal weekday energy use. A typical day is shown in Figure 10. Standby power has an even greater effect on weekends, when most lights are turned off throughout the day. Systems that attain very low standby power levels and those that innovate to shut off power to the luminaires in certain situations will achieve additional energy savings compared to the installed system. 


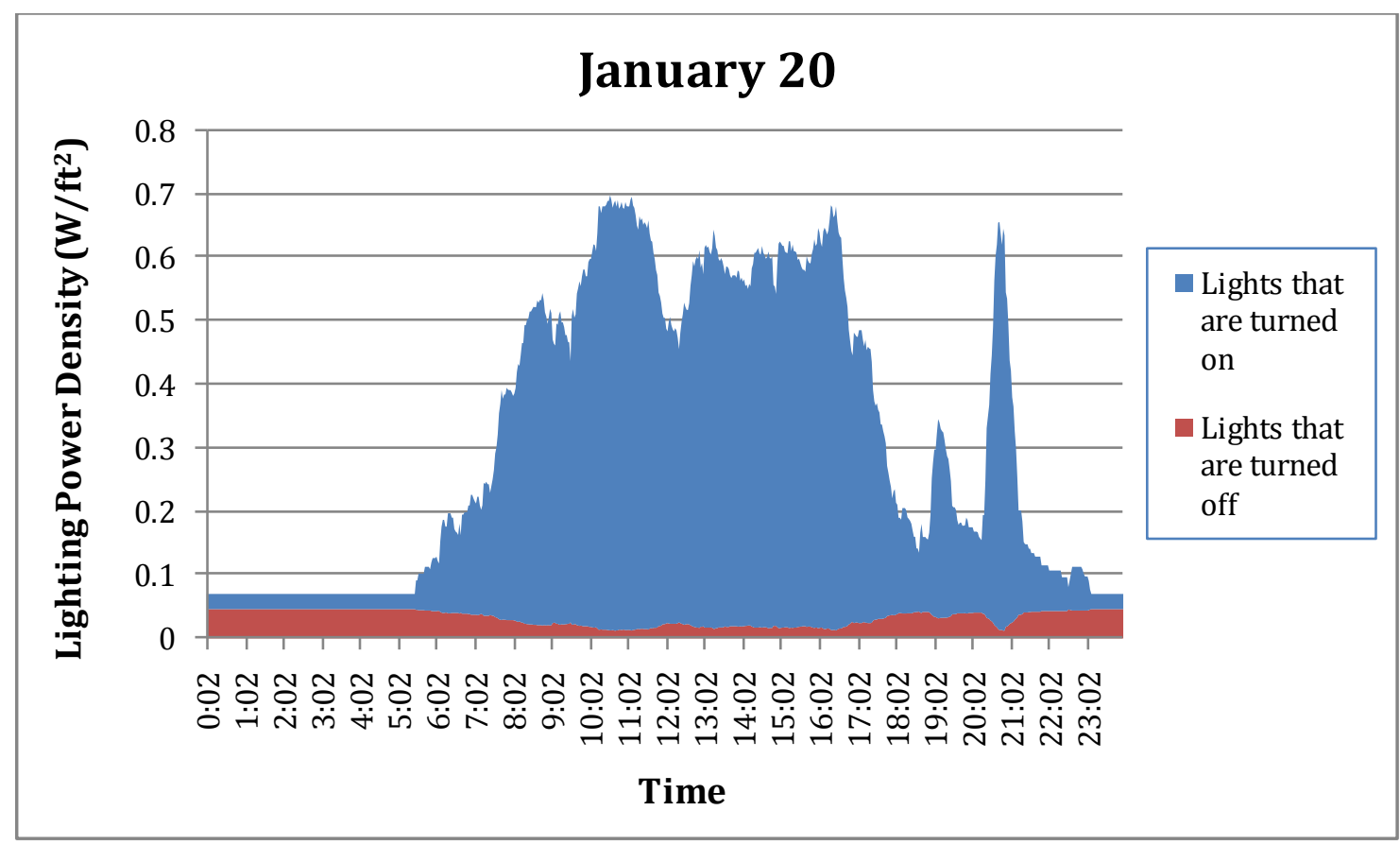

Figure 10: Stacked area plot of LPD on January $20^{\text {th }}$, split between standby and non-standby power. The lower area (in red) gives the power contribution of lights that are turned off, averaged over the floor area. The upper area (in blue) gives the power contribution of lights that are turned on. The upper edge of the blue area gives the total LPD. Lights at standby contribute approximately $10 \%$ of the day's energy consumption.

In the current WS installation, occupants have only very indirect control over their workstation lighting. They can request light level and timeout changes, but cannot adjust light levels day-to-day or override the central control system either through a computer interface or a wall switch. An occupant leaving at the end of the day cannot prevent the lights from staying on for an extra half hour during timeouts. Studies have found that providing personal controls in addition to occupancy sensors can decrease energy use significantly [3][4]. Adding personal controls to this installation, as GSA intends to do, shouldtherefore increase energy savings beyond the numbers reported here.

Dimming lights according to daylight levels would primarily affect workstations on the perimeter and in the east zone and would increase energy savings. On the other hand, implementing a typical control strategy that leaves uplights turned on in unoccupied cubicles during business hours would increase energy use.

\section{COST-EFFECTIVENESS}

WS luminairesare often very expensive because they require two dimming ballasts each as well as better optics and integr ated control sensors. By carefully selecting components from multiple sources and leveraging the DALI protocol, GSA has reduced the cost to purchase and install WS luminaires in existing buildings to about $\$ 450$ per luminaire $(\$ 400$ for the fixture and about $\$ 50$ for the associated control circuitry and systems). In this study luminaires are installed at one per just over 95 square feet, bringing the cost to $\$ 4.72$ per square foot. 
To calculate simple payback periods, we assumed a scenario in an open office with the GSA base system ( $2 \times 4$ recessed troffers) currently installed, as is typical of many GSA buildings. GSA is deciding if they should leave GSA base in place, retrofit with WS luminaires, or retrofit with GSA standard (the current standard retrofit option, with continuous, pendanthung direct/indirectluminaires). Retrofitting to install GSA standard is estimated to cost approximately $\$ 2$ per square foot.

Energy for a large office building in San Francisco typically costs $\$ 0.15 / \mathrm{kWh}$ (including demand). Relevant values assuming this cost of electricity are included inTable 8 . These calculations result in simple payback periods of 8.6 years for the WS system and 5.5 years for GSA standard. Payback periods for regions with different energy costs can be read from the graph inFigure 11.

\begin{tabular}{|c|c|c|c|c|c|}
\hline & $\begin{array}{l}\text { Installation } \\
\text { cost }\left(\$ / \mathrm{ft}^{2}\right)\end{array}$ & $\begin{array}{l}\text { Energy use } \\
\left(\mathrm{kWh} / \mathrm{ft}^{2} / \mathrm{yr}\right)\end{array}$ & $\begin{array}{l}\text { Energy } \\
\text { expenses } \\
\left(\$ / \mathrm{ft}^{2} / \mathrm{yr}\right)\end{array}$ & $\begin{array}{l}\text { Energy } \\
\text { savings } \\
\text { compared } \\
\text { to GSA base } \\
\left(\$ / \mathrm{ft}^{2} / \mathrm{yr}\right)\end{array}$ & $\begin{array}{l}\text { Simple } \\
\text { payback } \\
\text { period (yr) }\end{array}$ \\
\hline $\begin{array}{l}\text { WS luminaire } \\
\text { retrofit }\end{array}$ & 4.72 & 2.18 & 0.33 & 0.55 & 8.6 \\
\hline $\begin{array}{l}\text { GSA standard } \\
\text { retrofit }\end{array}$ & 2 & 3.45 & 0.52 & 0.36 & 5.5 \\
\hline GSA base & 0 & 5.85 & 0.88 & 0 & $\mathrm{~N} / \mathrm{A}$ \\
\hline
\end{tabular}

Table 8: Simple payback period calculations for the two retrofit options, assuming GSA base is currently installed and energy costs $\$ 0.15 / \mathrm{kWh}$. The simple payback period for installing WS luminaires is 8.6 years and for GSA standard is 5.5 years.

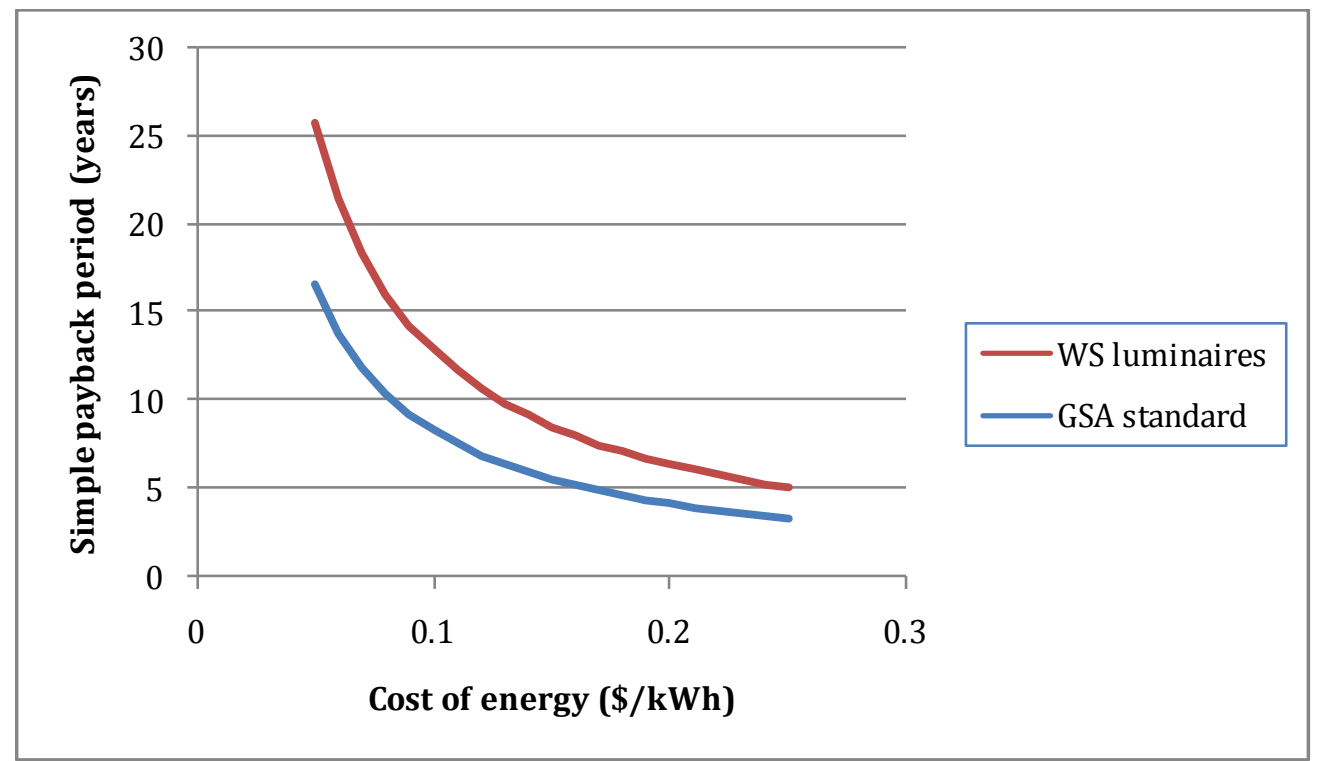

Figure 11: Simple payback periods for WS and GSA standard retrofits compared to an existing GSA base system. To achieve 15 year paybacks, electricity must cost at least $\$ 0.08 / \mathrm{kWh}$ for the WS system and $\$ 0.05 / \mathrm{kWh}$ for GSA standard. For 10 year paybacks, electricity must cost over $\$ 0.12 / \mathrm{kWh}$ for the WS system and over $\$ 0.08 / \mathrm{kWh}$ for GSA standard.

The two retrofit options can also be compared to each other: the payback period for the additional investment associated with WS luminai res based on the additional savings the 
WS system achieves compared to GSA standard can be calculated. The additional investment in the WS system is $\$ 2.72 / \mathrm{ft}^{2}$ and the energy savings compare dto GSA standard come to $\$ 0.19 / \mathrm{ft}^{2} / \mathrm{yr}$ (assuming $\$ 0.15 / \mathrm{kWh}$ ), resulting in a simple payback period between the two retrofit options of about 14 years.

Payback calculations exclude the effect of HVAC savings associated with reduced lighting loads, which will shorten the payback periods associated with both retrofit options, particularly the WS system. The WS system's dimmable ballasts and control system make reducing lighting loads during PG\&E's demand response events a possibility, which would provide additional savings.

Maintenance costs will have a largely unknown impact on payback periods. The current WS system has an extensive five-year warranty that includes maintenance. When the warranty expires, the skill level of maintenance personnel will have to increase somewhat for the WS system compared to GSA standard; the impact of WS lighting on maintenance hours is unknown. The WS control system can generate automatic work orders for replacing equipment, which can streamline maintenance somewhat.

The simple payback period for retrofitting with WS lighting is higher than typical targets and higher than that of GSA standard. Basing investment in WS lighting on energy alone will therefore be a challenge without significant reductions in costs, increases in energy savings, or a mandate to reduce greenhouse gas emissions. Using cheaper fixtures and/or uplights without dimming capabilities would reduce the cost of WS lighting, though using fixed output uplights would increase energy use. Mass production as WS systems become more common could reduce costs as well. On the energy side, HVAC savings, time-of-use rates, and potential demand response savings will improve the WS system's simple payback period somewhat. Further, previous stu dies have found that adding personal controls (which would not increase installation costs) and photosen sors (which would) can significantly increase energy savings compared to using occupancy sensors alone [3][4]. Adding these features could potentially make the cost equation for a WS retrofit much more favorable.

Finally, WS lighting makes large energy savings a possibility without compromising workspace lighting conditions, making it an excellent option for projects in which this is a priority.

\section{Photometric Analysis}

\section{METHODOLOGY}

Two levels of photometric analysis were conducted. First, 27 WS workstations in the north section of the study area and 20 GSA standard workstations on another floor were surveyed with a handheld illuminance meter at the front corners of the central desk section. WS measurements were taken with overhead lights set to $100 \%$ and currently used levels. Twenty-one of the 27 WS cubicles used default light settings, allowing for an analysis of light levels under the defaultsettings as well. Throughout, measurements were taken with the principal undercabinet light both on and off. Objects on the desks and in the workstations were not moved, and measurements were made without anyone seated at the desk. 


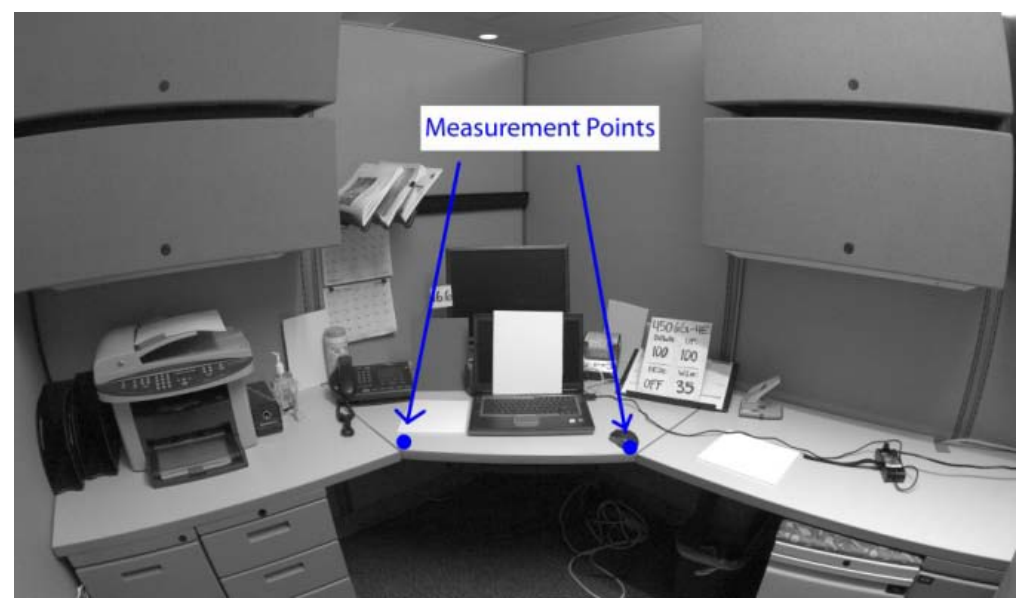

Figure 12: Points surveyed with a handheld illuminance meter

Second, two workstations with WS luminairesin the south zone were photographed with a digital camera under various light conditions. The photographs were calibrated using a method developed by LBNL to produce luminance measurements. A white board placed on the desktop allowed for a rough conversion from luminance to illuminance:luminances of the outside edges of the board and the adjacent desk surface were compared and the white board luminance and illuminance were metered in order to develop a factor to convert desktop luminance into illuminance. For each workstation, the luminances of exposed areas of the desk were multipliedby this calculated value and then analyzed to obtain estimated desktop illuminance distributions. This conversion will not be entirely accurate due to the non-Lambertian component of the desk surface reflectance and the various assumptions involved, but should be reasonable since there is little dir ect glare on the desk.

We are aware that this method will only give approximate illuminance values, and approach results with this caveat in mind. Precedence should be given to the han dheld illu minance meter measurements. We hope that this second set of measurements provides supplementary insight about illuminance distributions.
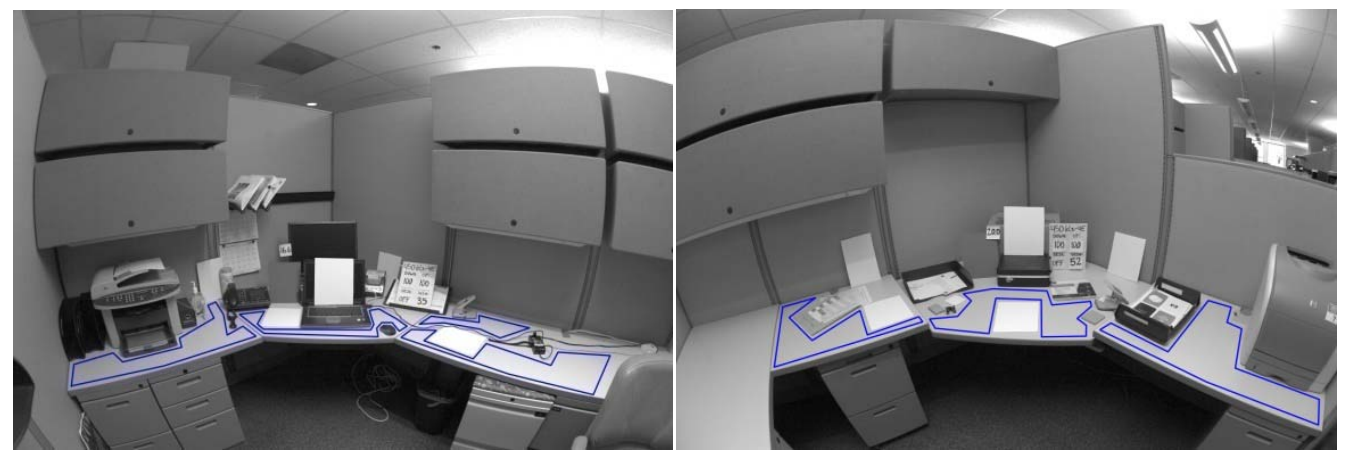

Figure 13: Areas analyzed for workstations 35 (left) and 52 (right) are outlined on the desk surfaces. In both cases, the luminaire is oriented parallel to the wall containing the cubicle entrance. This means parallel to the right wall in the photograph of workstation 35, and parallel to the left wall in the photograph of workstation 52.

Both sets of photometric measurements are conservative compared to many illuminance measurements in other studies. Wide variation in measurement location and conditions make direct comparison between projects difficult, and many measurements take place in empty cubicles without cabinets or objects on the desk and/or with low or nonexistent 
partitions. With only a few exceptions (including workstation 52), the measurements presented here take place under real-world conditions in currently occupied cubicles. High partitions, cabinets, and desktop clutter make these measurements lower than they would be under less realistic testing conditions.

\section{RESULTS}

The results of the handheld illuminance meter survey are presented in Figure 14. Since measurements took place at the front corners of the desk, where shadowing was less, values lie towards the high end of each desk's illuminance distribution. With the WS luminaires at full power and the undercabinet light turned off, the average illuminance at measurement points is just over 600 lux, while at default settings it drops to 474 lux. On average, theGSA standardluminaires provide 336lux without the undercabinet light. The undercabinet light adds approximately 60 lux on average, though this varies considerably according to location. The spread in illuminance levels under each setting can be largely attributed to differences in layout, undercabinet lighting, and desktop clutter. The low illuminances in the "user setting" category for the WS luminairescome from workstations with lights intentionally set well below default levels based on occupant requests. Aside from those workstations, light levels from overhead lightingin all of the WS cubicles stay above 350 lux, while those in GSA standard cubicles drop below 350 luxabout $60 \%$ of the time.

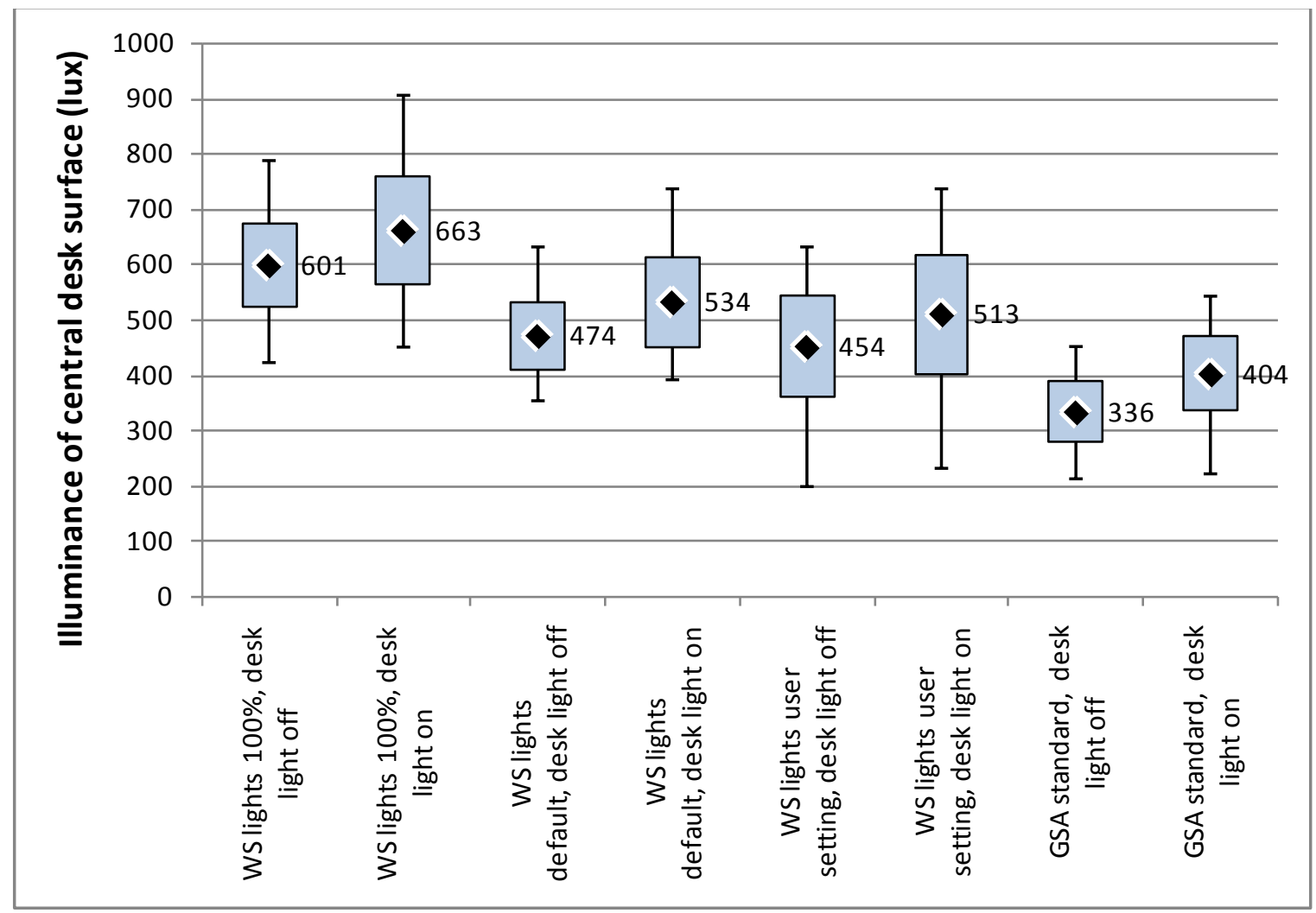

Figure 14: Metered illuminance of points at the front cornersof the central desk area. The black diamonds and adjacent values give the mean, blue rectangles extend one standard deviation from the mean in each direction, and bars cover the entire range of data. Low illuminances in the "user setting" categories are associated with occupants who requested low light levels. 
Digital photographs of two workstations were calibrated to provide luminance levels, from which illuminance levels on the desk surface were estimated. A false color image showing luminance levels in workstation 35 under full power light settings is shown in Figure 15. The large cabinets and objects on the desk contribute to shading the desk surface somewhat.

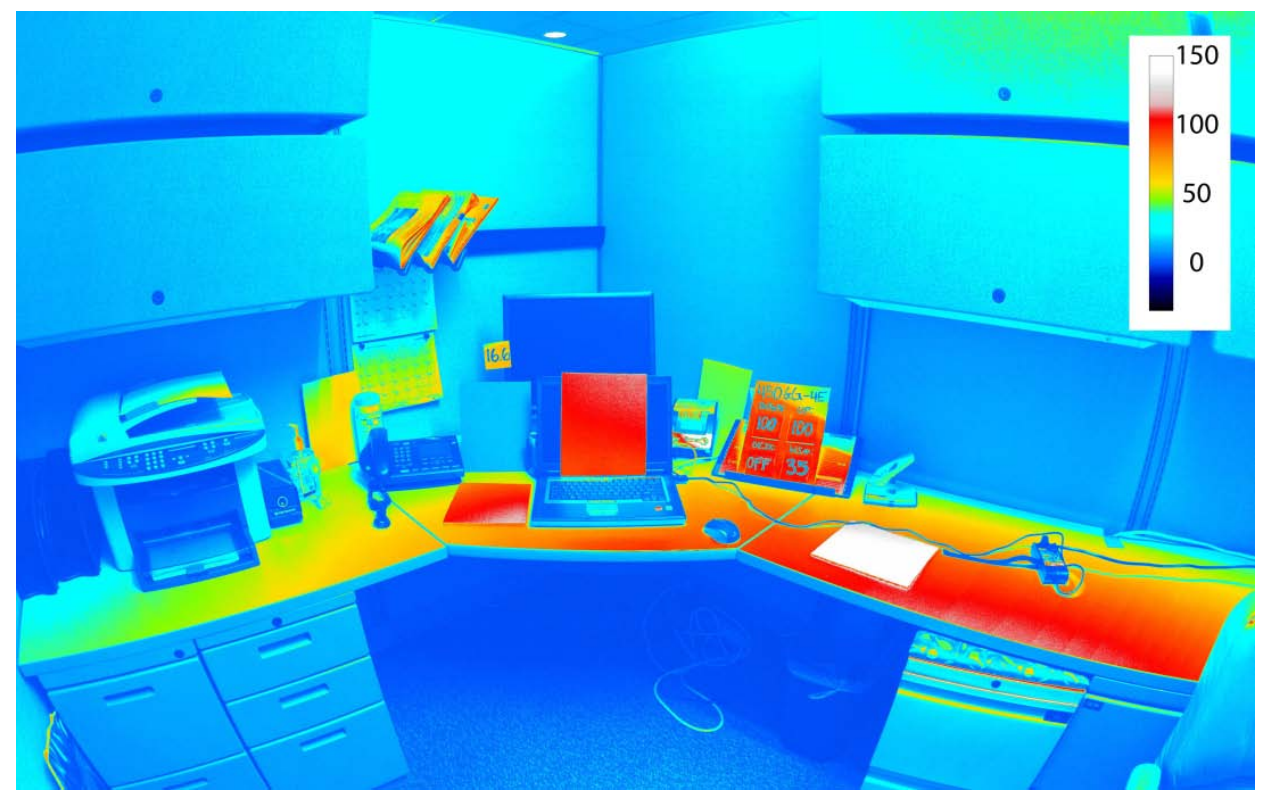

Figure 15: False color image of workstation 35 with overhead lights at $100 \%$ and undercabinet light off. Calibration bar is in candelas per meter squared.

Illuminance levels for the exposed desktop of each workstation were calculated as discussed above and are presented in Table 9. Theilluminance on the desk surface is clearly widely distributed. At default settings, the average illuminance for each section exceeds IESNA recommended levels of 300 luxfor general office lighting except in the underlit "left" section, which is shaded by cabinets and a printer in one workstation and cabinets in the other[7]. Illuminance towards the back of each section and in the left section of workstation 35 drops below recommended values, but at the front of the desk levels generally stay well above recommended minimums.

\begin{tabular}{|c|c|c|c|c|}
\hline \multirow[b]{2}{*}{ Condition } & \multirow[b]{2}{*}{ Location } & \multicolumn{3}{|c|}{ Estimated illuminance (lux) } \\
\hline & & Mean & Minimum & Maximum \\
\hline \multirow{3}{*}{$\begin{array}{l}\text { Full power (both } \\
\text { downlights and } \\
\text { uplights } 100 \% \text { ) }\end{array}$} & Central desk area & 410 & 280 & 513 \\
\hline & Left desk area & 313 & 163 & 424 \\
\hline & Right desk area & 448 & 193 & 584 \\
\hline \multirow{3}{*}{$\begin{array}{l}\text { Default setting } \\
\text { (downlights } 75 \% \\
\text { and uplights } 50 \% \text { ) }\end{array}$} & Central desk area & 351 & 239 & 442 \\
\hline & Left desk area & 267 & 134 & 366 \\
\hline & Right desk area & 385 & 172 & 516 \\
\hline
\end{tabular}

Table 9: Estimated mean, minimum and maximum illuminance of exposed desk surfaces in two workstations under both full power and default lighting conditions. Results are the average of results from the two workstations. Undercabinet lights were turned off throughout. 
A subtler interpretation can be reached by studying workstation 35 in more detail. The illuminance distributions on the desk surface at default and $100 \%$ light levels are shown in Figure 16. Both show a small concentration of points with low illuminance, another larger concentration with somewhat higher illuminance, and a final concentration with high illuminance. Both distributions are also mapped in terms of the percentage of desk surface with at least a given illuminancevalue in Figure 17. For default light settings, the middle $60 \%$ of desktopilluminances ranges from approximately 200-400 lux, while at full power the middle $60 \%$ covers approximately $250-500$ lux.
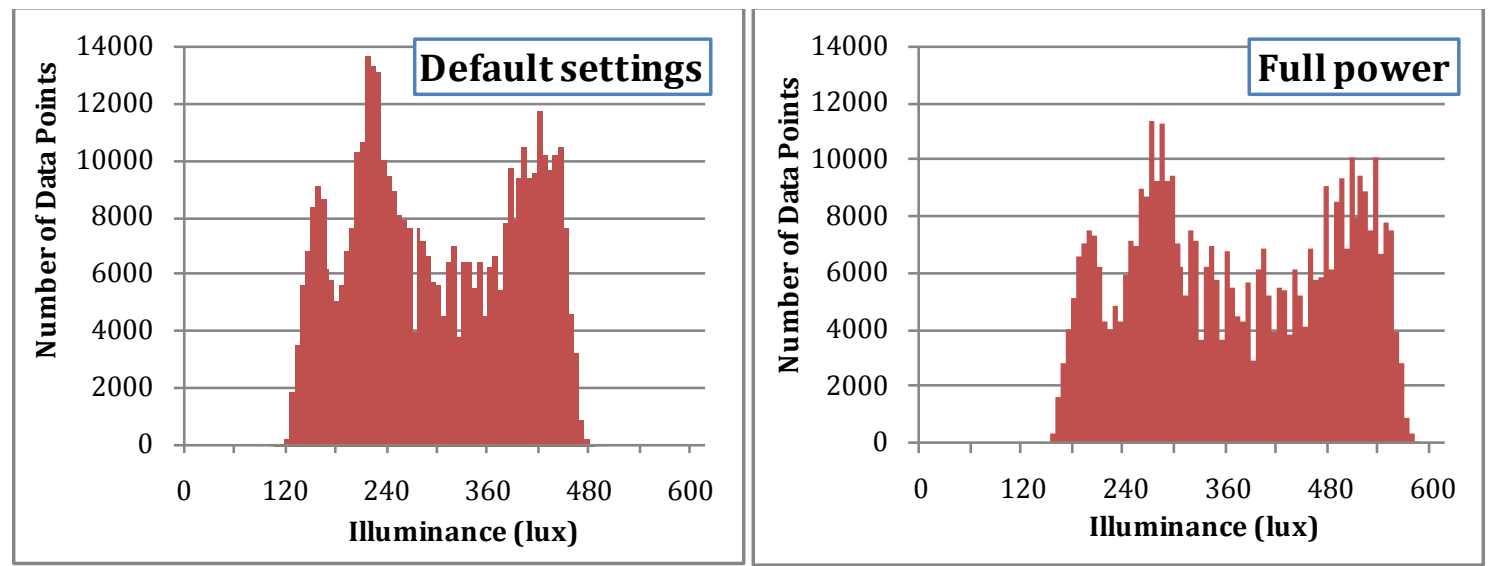

Figure 16: Estimated illuminance distribution of workstation 35, with lights at default settings (uplight at $50 \%$, downlights at $75 \%$ ) on left, and lights at full power on right

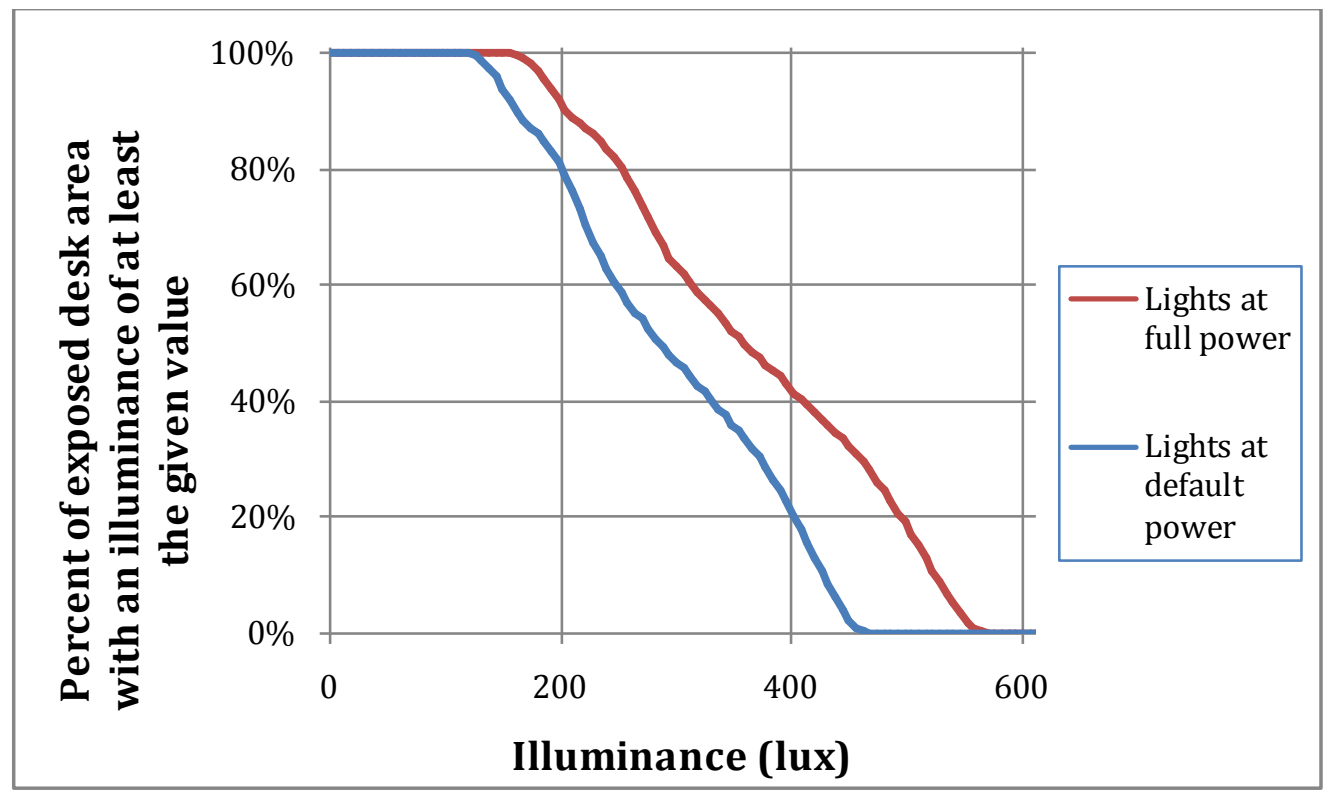

Figure 17: Percent of exposed desk surface at workstation 35 with at least the illuminance value on the horizontal axis. For default light settings, about $20 \%$ of the measured surface is below 200 lux and about $20 \%$ is above 400 lux. 


\section{DISCUSSION}

The first phase of photometric analysis demonstrates that the WS lighting system provides higher light levels than the GSA standard system. The WS system at default settings provides IESNA appropriate light levels at the front of the central desk section, even with real-world layout and clutter. All WS measurements except those in workstations with occupant-requested lower light levelsrecorded illuminances greater than 350 lux, while mostGSA standard measurements fellbelow 350 lux. By focusing light in individual workstations, the WS system can save energy without compromising light levels in side the workstations in a way that GSA standard cannot. As a result, WS luminaires provide a viable way to move towards increasing levels of energy savings and greenhouse gas reductions without sacrificing workspace light levels. As discussed earlier, these illuminance measurements are conservative with respect to common comparisons, which often take place without cabinets, high partitions, or workstation clutter.

Measurement location matters as well, of course. Workstation layout, luminaire orientation, and desktop objects have a large impact on illuminance distributions. In the two WS cubiclesmonitored more closely, light levels vary widely across the exposed desk surface. Illuminance distributions show areas with low light levels at the back of the desk and near cabinets in addition to well-illuminated areas.

Studies have shown that personal preferences for workspace light levels vary widely [1][9]. The low light levels requested by some occupants even without personal controlsreinforce this concept. One significantbenefit of workstation-specific lighting is that the control system can easily adjust light levels on a workstation-by-workstation basis, allowing people to work under their preferred lighting conditions even in a large open office.This installation's relatively high installed LPD also accommodates people who want higherthan-default light levels without compromising overall energy use. In a well-commissioned installation, providing WS lighting will not only save energy, but will allow occupants to improve their lighting conditions; in the process, occupant satisfaction and acceptance of the control system should increase.

Nevertheless, somepotential concerns remain about light conditions in a WS system that were not directly evaluated in this report. First, locating luminaires only above workstations has left the corridors between rows of cubicles fairly dark, a trend in some ways inherent to the WS vision of concentrating light in workstations where people spend most of their time. Second, the installed system leaves a blotchy or spotted ceiling pattern, shown in Figure 18, due both to irregular occupancy patterns and to the fact that the uplights have a fairly small spread.If desired, these concerns could be ameliorated by providing additional corridor lighting and/or dimming rather than turning off ambient lights during work hours. These changes would of course increase energy use. 

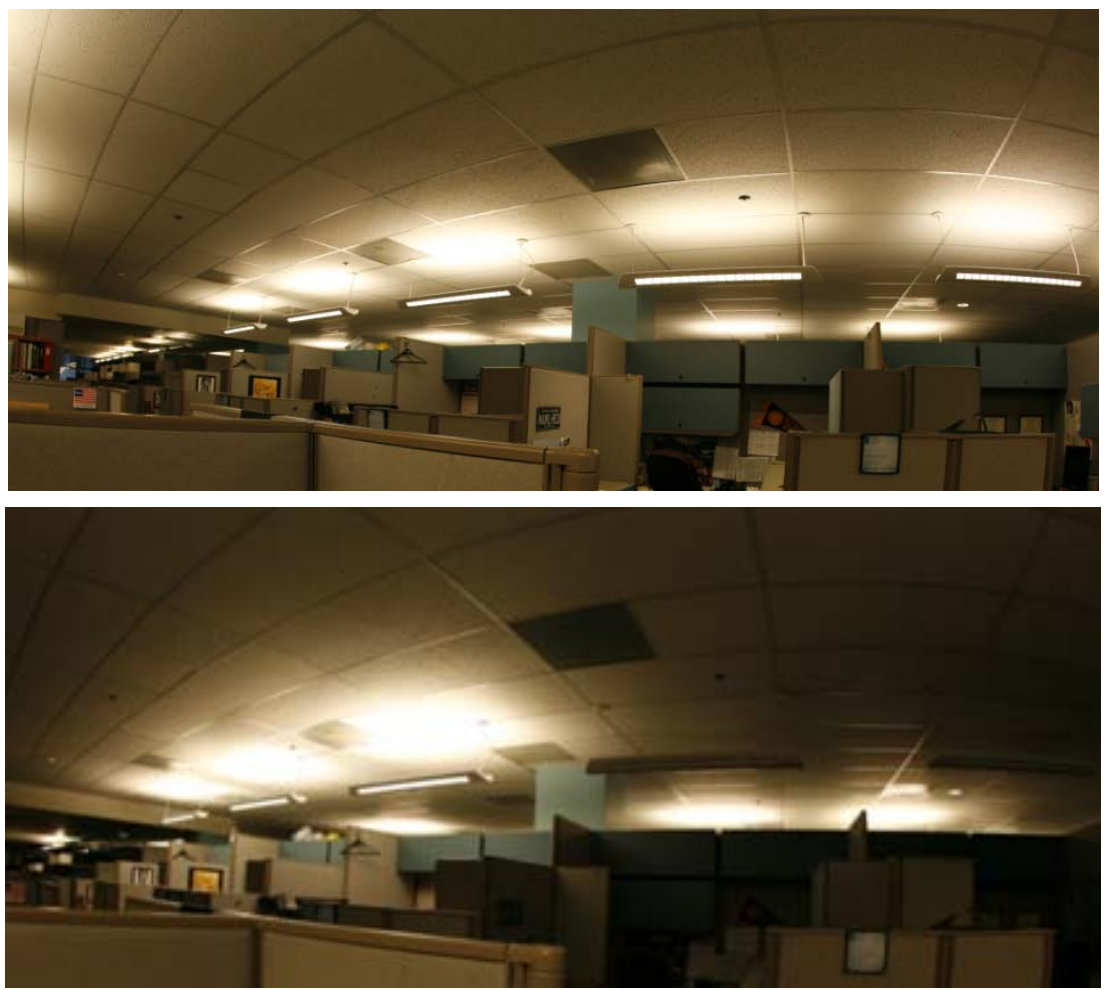

Figure 18: View of the ceiling with all nearby luminaires turned on (above) and with several luminaires turned off (below).

\section{Occupant Survey}

\section{METHODOLOGY}

An occupant survey designed by researchers at the Pacific Northwest National Laboratorywas administered in late February and early March to determine occupant responses to the installedWS and GSA standard systems. The survey was based on the work of the Light Right Consortium project and had in put from researchers at the National Research Council of Canada and the Lighting Research Center. It contained 38 multi-point rating and multiple choice type questions as well as space for comments. The survey and complete results are included in Appendices B and C, respectively. Invitations were sent to 153 people on the $3^{\text {rd }}$ and $4^{\text {th }}$ floors of the Philip Burton Federal Building via email, and 91 clicked on the link to take the survey, making the overall response rate about 59\%.

Survey respondents work on the $3^{\text {rd }}$ and $4^{\text {th }}$ floors of the building and have either recessed troffer fixtures, the GSA stand ard lighting system, or the WS system. They were divided according to their overhead lighting type based on the photograph they selected in the eighth survey question: "Which of the following types of lighting fixtures most closely resembles the general lighting in your immediate workspace?" For the purposes of this study, respondents who selected recessed troffer fixtures as their overhead lighting system were excluded since those lights are present mostly in private offices. Occupants who selected "Other (picture not shown)" were eliminated from analysis as well. This left48occupants who selected WS luminairesout of 78 invited occupants with WS luminaires( $62 \%$ response rate) and 12 occupants who selected the GSA standard system 
out of 46 invited occupants with GSA standard lighting ( $26 \%$ response rate). Both systems are installed only in open-office areas. Only the results for these two groups of occupants are presented here.

As discuss ed earlier, the GSA standardsystem has continuous rows of direct/indirect pendant-hung luminaires spaced 8-feet apart on center. It is installed on the 3 rd floor in an open cubicle area almost identical to the WS test area in terms of layout, daylight levels, task lights, and surface materials. It provides low levels of ambient light throughout the office area and does not allow occupants to control the overhead lights.

The small sample size and low response rate for the GSA standard system should be taken into account when evaluating these results, which also depend upon occupants having selected the correct lighting fixture for their workspace. We were not able to establish the statistical significance of the observed differences in occupant response, so results should be treated as qualitative.

\section{RESULTS}

Complete results are included in Appendix C, and selected results are presentedbelow. Percentages are calculated out of the number of occupants who responded to a given question, and may not add to $100 \%$ due to rounding.
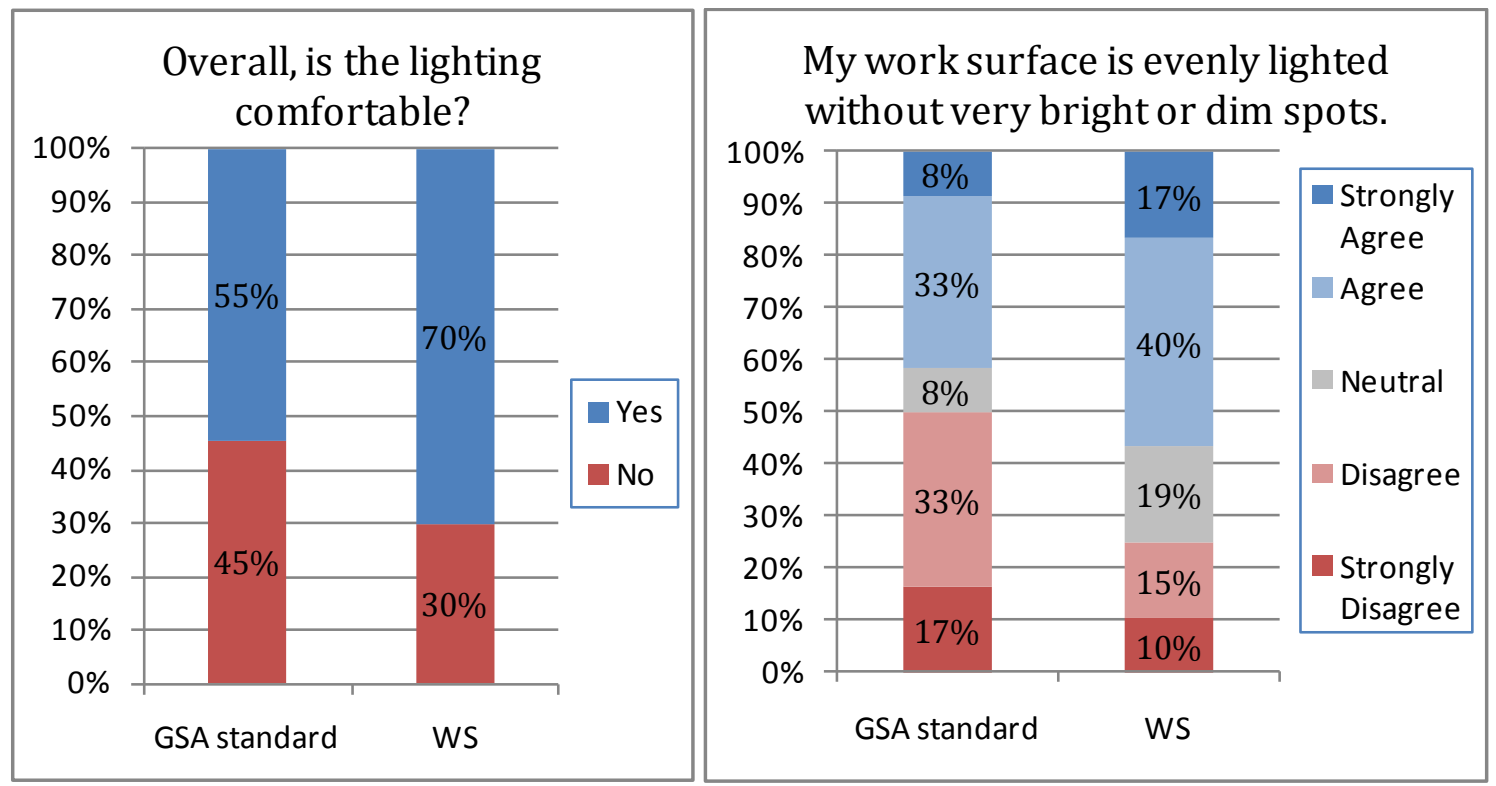

Figure 19: Responses to questions about the overall quality of the lighting system. Higher percentages of people with WS lighting find the lighting comfortable, and $57 \%$ agree or strongly agree that their workstation is evenly lighted compared to $41 \%$ of respondents with GSA standard lighting. Notably, $\mathbf{5 0 \%}$ of the GSA standard respondents disagree or strongly disagr ee that their workstation is evenly lighted compared to $25 \%$ of WS respondents. 


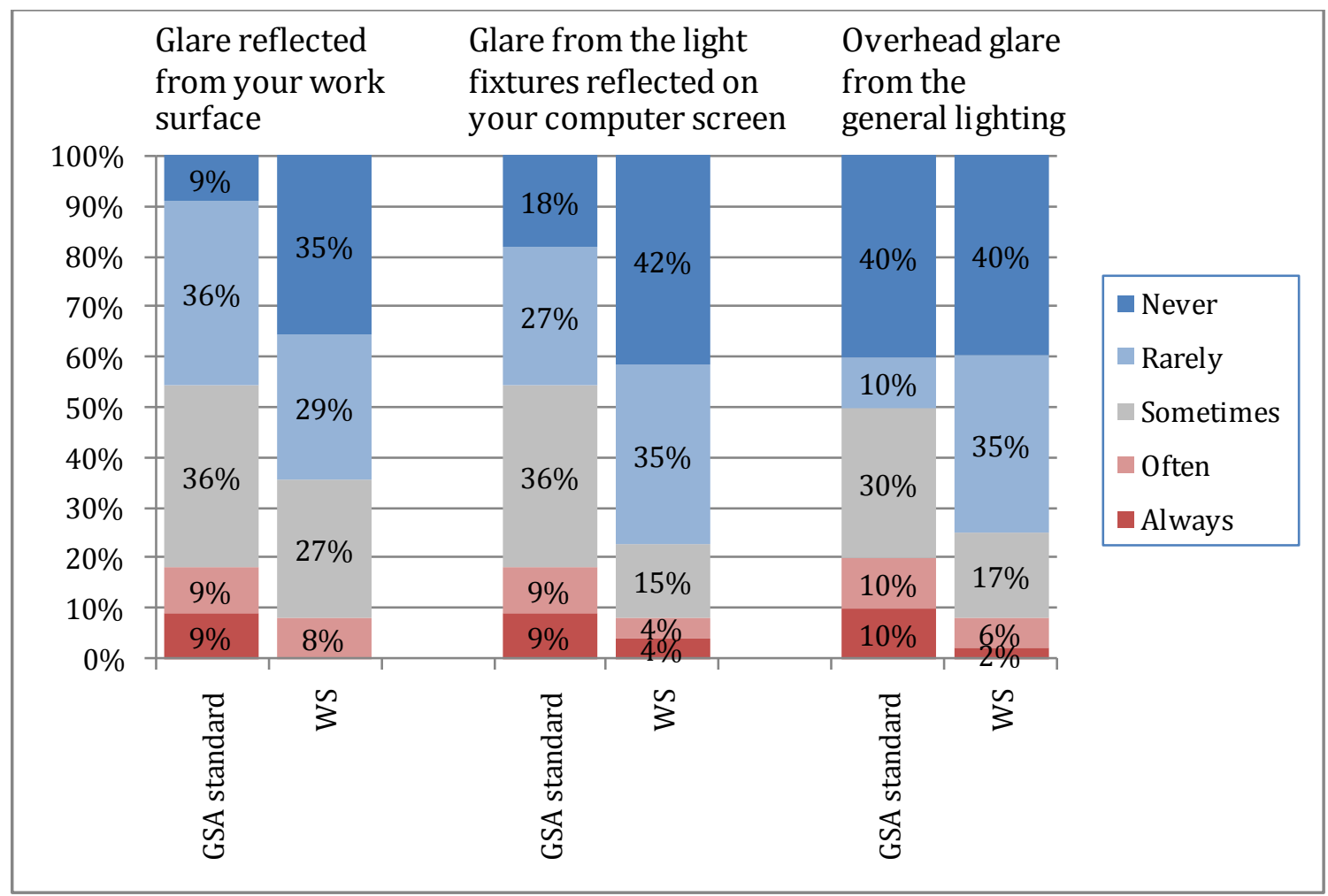

Figure 20: Responses to the question, "How often do you experience any of the following conditions when in your personal workspace during an average day?" The WS system generates lower levels of perceived glare throughout. Of particular interest is that 77\% of WS respondents "rarely" or "never" experience glare from fixtures reflected on their computer screens, compared with only $45 \%$ of GSA standard respondents. 


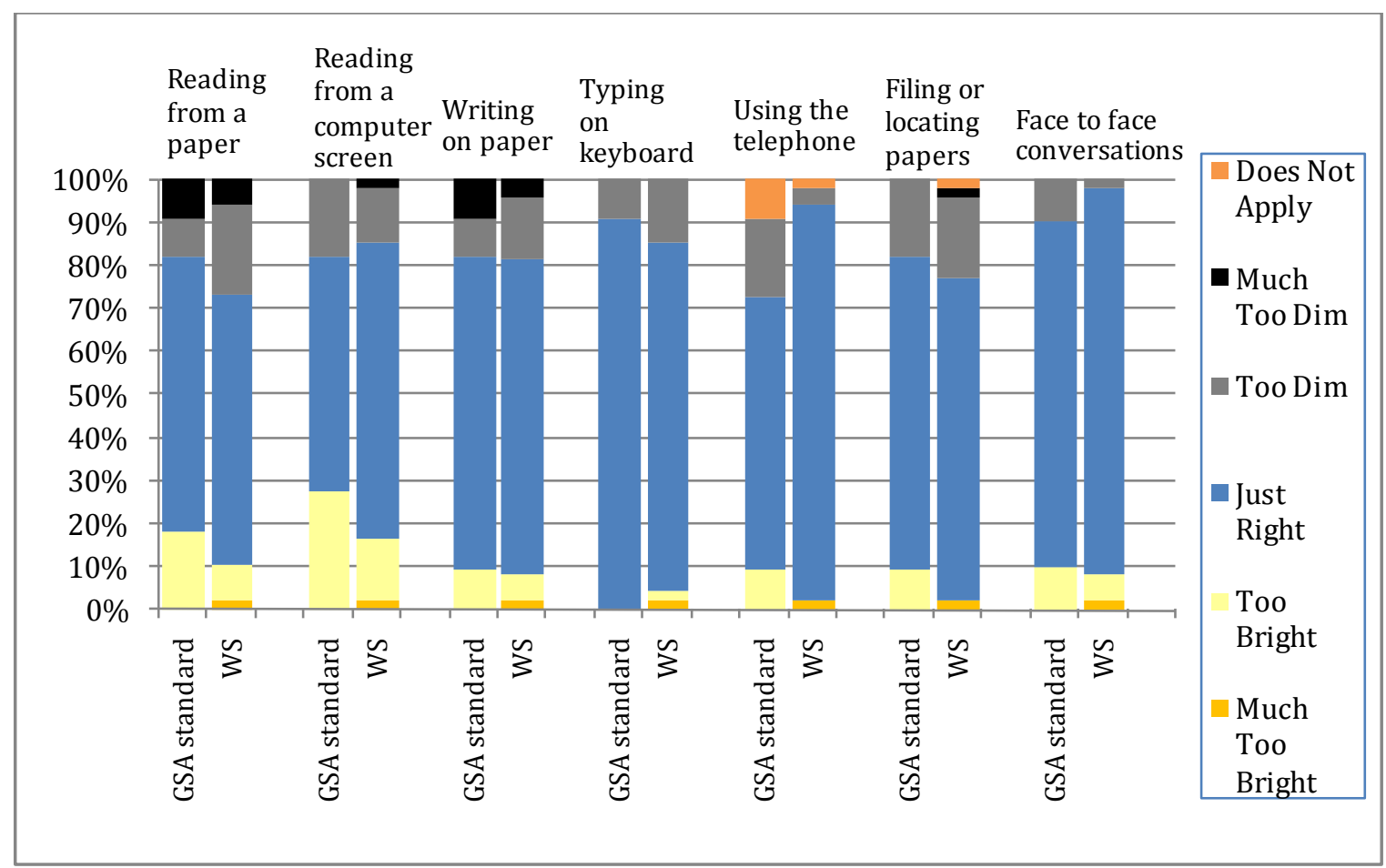

Figure 21: Responses to the question, "How would you rate the lighting in your workstation for each of the following tasks?" In each category and for both lighting systems, a majority of respondents selected "Just Right". While responses may remain consistent partially due to survey fatigue, both systems seem to provide acceptable light levels for a variety of typical office tasks.

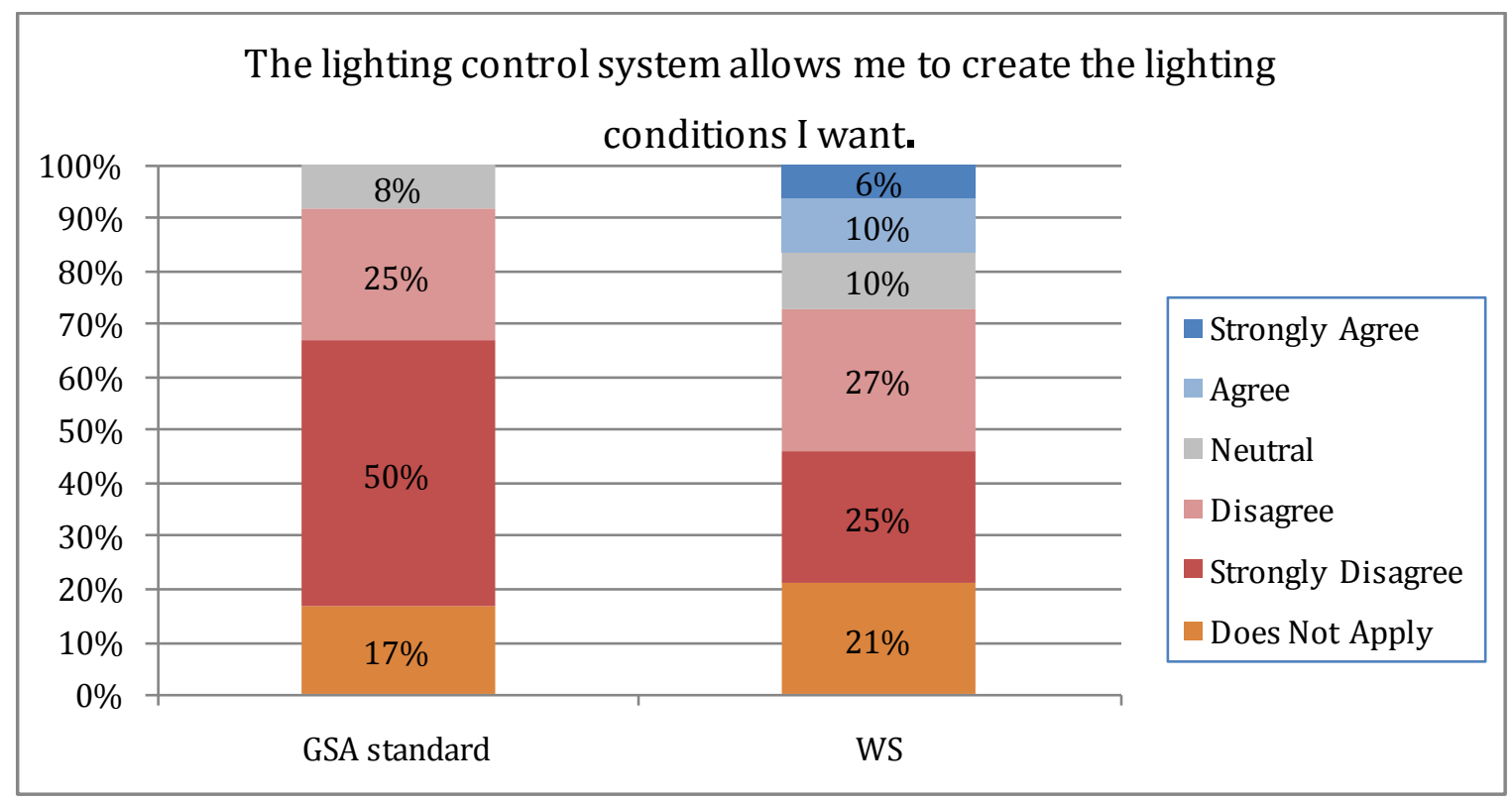

Figure 22: Responses to the question, "The lighting control system allows me to create the lighting conditions I want." While GSA standard occupants have less control, occupants with both types of lighting are clearly dissatisfied with the installed control systems, with only $16 \%$ of WS and $0 \%$ of GSA standard respondents selecting "agree" or "strongly agree". 


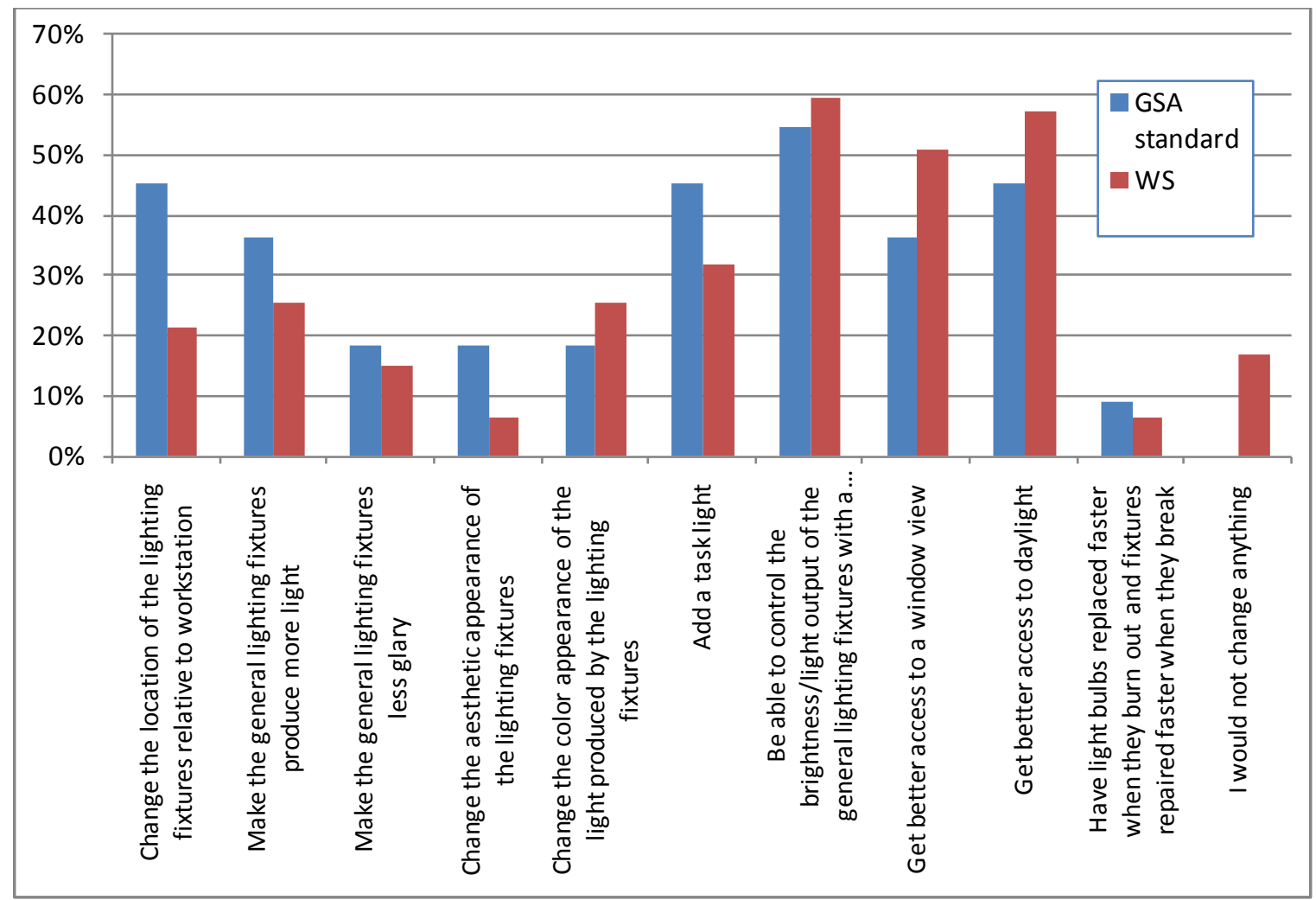

Figure 23: For each lighting system, the percentage of respondents who selected a particular answer to the request, "If you could change the lighting in your office, what would you do? Please check all that apply." For both lighting types, the largest group of occupants selected improved controls. Large numbers of occupants wanted access to daylight as well. Occupants with the GSA standard system were more likely to want lighting fixtures moved, increased light, more aesthetically pleasing fixtures, and additional task lights. Occupants with WS lighting were more likely to want window and daylight access and to modify the color appearance of their light. $17 \%$ of the WS respondents who answered this question said they would not change anything.

Six WS occupants (about 20\%) and five GSA standard occupants (about 40\%) responded to a final question that solicited additional comments about the lighting system. WS occupants expressed dissatisfaction with light distribution in the office as a whole and complained of sensors that turned lights off in occupied workstations. GSA standard occupants expressed interest in more light and more control over their lights.

\section{DISCUSSION}

Overall, occupants with WS lighting appear more satisfied than occupants with GSA standard lighting. They are more likely to find their lighting system comfortable and evenly distributed, less likely to experience glare associated with the lighting system, less likely to want the location and look of their lighting fixtures adjusted, and less likely to want an additional task light. These trends suggest that the WS system successfully provides more desirable workstation illumination than GSA standard. The effort to concentrate light in each workstation appears to succeed in terms of improving light conditions for occupants working at their desks.

The survey did not explicitly address occupant reactions to light in the corridors and overall office area, a point of concern for a WS system that does not include corridor lighting and 
that shuts both task and ambient lamps off on a workstation-by-workstation basis. Two free response comments critiqued the dark hallways and the experience of working alone in a row of cubicles surrounded by dark workstations. These responses suggest the existenceof dissatisfaction with the overall lighting that was not exposed by the survey. Future projects could improve overall office lighting by providing additional corridor lighting and/or leaving uplights turned on to a low level during work hours. The survey did not address the effect that adjacent cubicle light switching had on occupants; more res earch should be conducted to determine occupant reactions to this switching. If necessary, occupant disturbance could be mitigated by extending fade times.

Occupants with both systems clearly want more and better control over their lighting conditions. Only $16 \%$ of WS occupants and $0 \%$ of GSA standard occupants agreed or strongly agreed with the statement, "The lighting control system allows me to create the lighting conditions I want." Further, 60\% percent of WS occupants and 55\% of GSA standard occupants selected personaldimming control as something they wanted changed about their lighting system. While this trend highlights a significant limitation of the WS system as currently implemented, it also supports the use of WS lighting over uncontrolled lighting such as GSA standard in general.One of the main benefits of typical WS lighting systems is to provide occupants with personalized control over their lighting conditions, even in an open-office setting.

\section{Conclusion}

As the demand to save energy increases, workstation-specific lighting offers a way to achieve large savings in open offices without reducing the quality of workspace lighting conditions. WS lighting focuses light when and where it is need ed and takes great advantage of savings opportunities in low-occupancy and variable occupancy workspaces. This study demonstrates that WS lighting can achieve large energy savings in an open office compared to an uncontrolled, low power density alternative while providing higher light levels and improving occupant satisfaction.

Although not yet implemented in this installation, personal taste and controls can be elegantly accommodated in a WS lighting system. Occupants can set and adjust light levels as they see fit, working under a wide range of preferred conditions even in an open-office setting.

The installation discussed here demonstrates one of many possible approaches to WS lighting. Adding personal controls or daylighting, providing additional corridor lighting, and changing the control strategy to make ambient light levels more consistent will affect energy use and occupant satisfaction. Cubicle size, layout, and the specifics of the installed ballasts, sensors, lamps, and fixtures will change the equation as well.

Basing investment in the in stalled WS system on energy alone will be a challenge without significant reductions in installation costs, increases in energy savings, or a dir ective to reduce greenhouse gas emissions. Higher energy savings can be achieved by lowering standby losses, providing per sonal controls, incorporating daylighting, improving commissioning, and reducing timeouts. Further, occupants' lighting conditions should play a key role in retrofit decisions, and the WS system's ability to simultan eously save energy and create a positive luminous environment in workstations should give it an edge over many uncontrolled alternatives. 


\section{References}

[1] PR Boyce, NH Eklund, and SN Simpson, "Individual Lighting Control: Task Performance, Mood, and Illuminance," Journal of the Illuminating Engineering Society, pp. 131-142, 2000.

[2] Department of Energy, "2007 Buildings Energy Data Book, Table 1.3.3," 2007. http://buildingsdatabook.eren.doe.gov.

[3] AD Galasiu and GR Newsham, "Energy savings due to occupancy sensors and personal controls: A pilot field study," in Lux Europa 2009, 11th European Lighting Conference, Istanbul, 2009, pp. 745-752.

[4] AD Galasiu, GR Newsham, C Suvagau, and DM Sander, "Energy Saving Lighting Control Systems for Open-Plan Offices: A Field Study," Leukos, vol. 4, no. 1, pp. 7-29, 2007.

[5] New Buildings Institute, "Advanced Lighting Guidelines 2003, Table 8.4," 2003. http://www.newbuildings.org.

[6] GR Newsham, JA, Arsenault, C Veitch, and C Duval, "Effect of dimming control on office worker satisfaction and performance," in IESNA Annual Conference, Tampa, 2004, pp. $19-41$.

[7] MS Rea, The IESNA Lighting Handbook, Ninth Edition. New York: IESNA, 2000.

[8] F Rubinstein, D Bolotov, M Levi, K Powell, and P Schwartz, "The Advantages of Highly Controlled Lighting for Offices and Commercial Buildings," in 2008 American Council for Energy-Efficient Economy, Pacific Grove, CA, 2008.

[9] JA Veitch and GR Newsham, "Preferred luminous conditions in open-plan offices: research and practice recommendations," Lighting Research and Technology, vol. 32, pp. 199-212, 2001.

\section{Acknowledgements}

This work was supported by the US General Services Administration (Region 9), the Assistant Secretary for Energy Efficiency and Renewable Energy's Federal Energy Management Program of the U.S. Department of Energy under Contract No. DE-AC0205CH11231, and the California Energy Commission's Demand Response Research Center. We would like to thank Pacific Northwest National Laboratory for their work creating the occupant survey. 


\section{Appendix A-Light Use Calculations}

Estimate of the maximum impact of scheduling 11 uplights to turn on each evening. Lights turn on to 75\% "input" power for three hours, followed by typical timeouts. This calculation assumes that all lights have default power settings and that the lights would have otherwise stayed off. Energy use is averaged over the entire floor area.

\begin{tabular}{|r|r|r|r|r|r|r|}
\hline $\begin{array}{l}\text { "Input" } \\
\text { power } \\
\text { level }\end{array}$ & $\begin{array}{l}\text { Power } \\
\text { (W) }\end{array}$ & $\begin{array}{l}\text { Power } \\
\text { relative to } \\
\text { standby (W) }\end{array}$ & $\begin{array}{l}\text { Time per } \\
\text { day } \\
\text { (min) }\end{array}$ & $\begin{array}{l}\text { Floor } \\
\text { area } \\
\left.\text { (ft }{ }^{2}\right)\end{array}$ & $\begin{array}{l}\text { Number } \\
\text { of } \\
\text { lamps }\end{array}$ & $\begin{array}{l}\text { Extra energy use } \\
\text { (W-h/ft } / \mathrm{ft}^{2} / \text { day) }\end{array}$ \\
\hline $75 \%$ & 35.175 & 32.925 & 180 & 8200 & 11 & 0.133 \\
\hline $50 \%$ & 28.5 & 26.25 & 20 & 8200 & 11 & 0.012 \\
\hline $30 \%$ & 21.8 & 19.55 & 10 & 8200 & 11 & 0.004 \\
\hline
\end{tabular}

Total:

0.149

Estimate of the impact of all three lamps in asingle luminaire staying on for 12 extra hours per day. This calculation assumes that the luminaire had default power settings and would have otherwise stayed off, and does not take timeouts into account. Energy use is averaged over the entire floor area.

\begin{tabular}{|l|l|l|l|l|l|l|l|}
\hline Ballast & $\begin{array}{l}\text { "Input" } \\
\text { power } \\
\text { level }\end{array}$ & $\begin{array}{l}\text { Power } \\
\text { (W) }\end{array}$ & $\begin{array}{l}\text { Power } \\
\text { relative to } \\
\text { standby (W) }\end{array}$ & $\begin{array}{l}\text { Time } \\
\text { per day } \\
\text { (hours) }\end{array}$ & $\begin{array}{l}\text { Floor } \\
\text { area } \\
\text { (ft }^{2} \text { ) }\end{array}$ & $\begin{array}{l}\text { Number } \\
\text { of } \\
\text { lamps }\end{array}$ & $\begin{array}{l}\text { Extra energy use } \\
\text { (W-h/ft } \mathbf{f l a y}^{2}\end{array}$ \\
\hline $\begin{array}{l}\text { 2-lamp } \\
\text { ballast }\end{array}$ & 75 & 63.55 & 61.3 & 12 & 8200 & 1 & 0.090 \\
\hline $\begin{array}{l}\text { 1-lamp } \\
\text { ballast }\end{array}$ & 50 & 28.5 & 26.25 & 12 & 8200 & 1 & 0.038 \\
\hline
\end{tabular}

Total:

0.128 


\section{Appendix B-Occupant Survey}

The occupant satisfaction survey was sent via email link to 153 occupants, 91 of whom clicked the link between February 18 and March 8, 2010. The complete survey is compiled below:

\section{Privacy Statement}

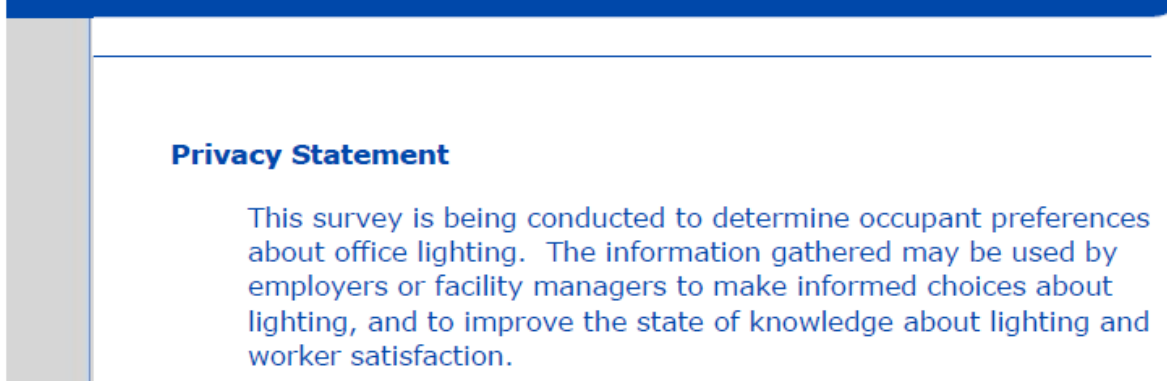

About this Survey

- Responses are anonymous - Your responses to this on-line survey will be sent directly to the survey administration company server which is not associated with and cannot be accessed by your employer. This ensures that your specific responses will never be available to the organization or individuals that you work for. Your responses will only be available as aggregated group information.

- Participation is Voluntary - This survey is entirely voluntary, and you are free to choose at any time whether or not to provide responses to the survey or individual questions.

- Your Rights - If you have questions about your rights as a participant of this research survey or this website, please email the Institutional Review Board at Pacific Northwest National Laboratory. A research specialist will respond to your question promptly.

Accept

\section{Lighting Satisfaction Survey}

What is your age?
30 or under
$31-40$
$41-50$
Over 50

What is your gender?

Female

Male

Back / Next 


\section{Lighting Satisfaction Survey}

On a typical day, how long are you in your personal workspace?
More than 6 hours
4-6 hours
2-4 hours
Less than 2 hours

Are you able to see out a window while sitting in your workspace?
Yes
No

Do you sit next to a window?
Yes
No

Which of the following best describes your personal workspace?
Cubicles in open area
Enclosed private office

Overall, is the lighting comfortable?
Yes
No

Which of the following types of lighting fixtures most closely resembles the general lighting in your immediate workspace?

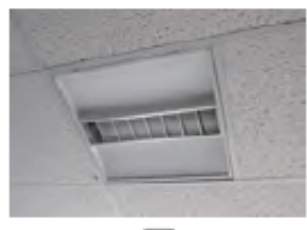

$\square$

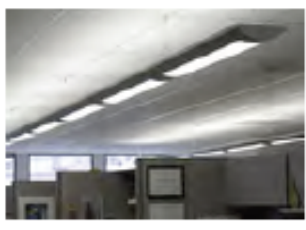

$\square$

Other (picture not shown)

Description of Overhead Lighting, if "Other."

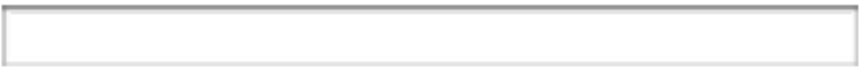

Back / Next

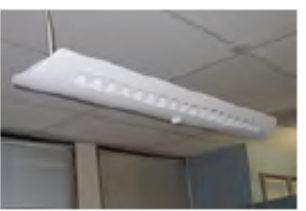

$\square$ 


\section{Lighting Satisfaction Survey}

Page 3 of 9

To what extent do you agree or disagree with the following statements about the lighting in your personal workspace? Please check "N/A" or "Not Applicable," if a given question does not apply to you.

\begin{tabular}{cccc|c|}
$\begin{array}{c}\text { Strongly } \\
\text { Disagree }\end{array}$ Disagree $\quad$ Neutral & $\begin{array}{c}\text { Strongly } \\
\text { Agree }\end{array}$ & $\begin{array}{c}\text { Does Not } \\
\text { Apply }\end{array}$ \\
& & &
\end{tabular}

My work surface is evenly lighted without very bright or dim spots.

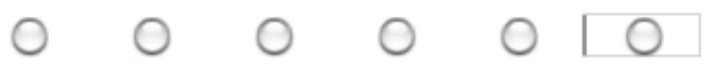

The lighting fixtures in the general office area around my workspace are nice-looking.

The light fixtures are too bright.

$0 \quad 0 \quad 0 \quad 0 \quad 0 \quad 0$

The lighting control system allows me to create the lighting conditions I want.

The lighting feels gloomy.

$0 \quad 0 \quad 0 \quad 0 \quad 0 \quad 0$

The lights flicker throughout the day.

The lighting helps create a good image for the organization.

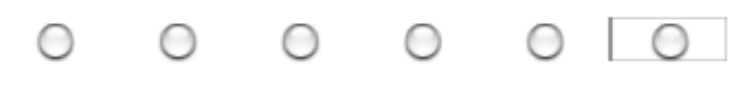

My skin is an unnatural tone under the lighting.

The room surfaces (walls, ceilings) have a pleasant brightness.

\section{Back / Next}




\section{Lighting Satisfaction Survey}

How would you rate the lighting in your workspace for each of the following tasks? Please check "NA," or "not applicable," if a given question does not apply to you.

\begin{tabular}{ccccc|c|}
$\begin{array}{c}\text { Much Too } \\
\text { Bright }\end{array}$ & $\begin{array}{c}\text { Too } \\
\text { Bright }\end{array}$ & $\begin{array}{c}\text { Just } \\
\text { Right }\end{array}$ & $\begin{array}{c}\text { Too } \\
\text { Dim }\end{array}$ & $\begin{array}{c}\text { Much Too } \\
\text { Dim }\end{array}$ & $\begin{array}{c}\text { Does Not } \\
\text { Apply }\end{array}$ \\
& & & & &
\end{tabular}

Reading from paper

Reading from a
computer screen

Typing on keyboard

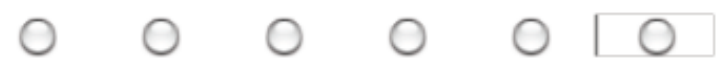

Using the telephone

$\begin{array}{lllllll}0 & 0 & 0 & 0 & 0 & 0\end{array}$

Filing or locating papers

Face to face

conversations

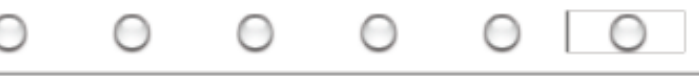

(n)

Back / Next 
Lighting Satisfaction Survey

Page 5 of 9

How often do you experience any of the following conditions when in your personal workspace during an average day?

For the purpose of answering these questions, consider the definition of glare to be unwanted light. Erg., noise is to sound, as glare is to light.

Never Rarely Sometimes Often Always

Glare reflected from your work surface

Glare from the light fixtures reflected on your computer screen

Glare from the window reflected on your computer screen

Overhead glare from the general lighting

Glare from your task lighting

Direct glare from a window

Direct glare from the light fixtures

Back / Next

Highly-Controlled Lighting

42 of 50

April 19, 2010 


\section{Lighting Satisfaction Survey}

Lighting comes in a range of colors, from a "warm" white to "cool" white. "Warm" light is often described as slightly yellow in appearance, and "cool" light is often described as slightly blue in appearance. Using the indicated color range, please indicate:

\begin{tabular}{ccccc|c} 
Very & Somewhat & & Somewhat & Very & Don't \\
Warm & Warm & Neutral & Cool & Cool & Know
\end{tabular}

What is the color appearance of the lighting in your personal workspace?

What would you prefer for the color appearance of the lighting in your personal workspace?

\section{Lighting Satisfaction Survey}

Page 7 of 9

How often do you experience any of the following conditions when in your personal workspace?

\begin{tabular}{|c|c|c|c|c|}
\hline & & About & About & \\
\hline Never & Rarely & $\begin{array}{c}\text { Once per } \\
\text { Month }\end{array}$ & $\begin{array}{c}\text { Once per } \\
\text { Week }\end{array}$ & $\begin{array}{l}\text { Every } \\
\text { Day }\end{array}$ \\
\hline
\end{tabular}

"Burning" or tired eyes after reading extensively

"Burning" or tired eyes after using computer extensively

I have to take a break to let my eyes recover

Headache that you think is caused by your lighting

Back / Next 


\section{Lighting Satisfaction Survey}

Page 8 of 9

If you could change the lighting in your office, what would you do? Please check all that apply.

Change the location of the general lighting fixtures

relative to your workstation

Make the general lighting fixtures produce more light

Make the general lighting fixtures less glary

Change the aesthetic appearance of the lighting fixtures

Change the color appearance of the light produced by the lighting fixtures

Add a task light

Be able to control the brightness/light output of the general lighting fixtures with a dimmer or high/low switch

Get better access to a window view

Get better access to daylight

Have light bulbs replaced faster when they burn out and fixtures repaired faster when they break

I would not change anything

Back / Next

\section{Lighting Satisfaction Survey}

Page 9 of 9

Please feel free to submit any other comments about your lighting below:

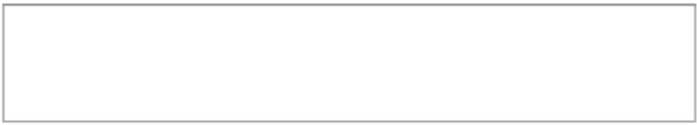

Please feel free to submit any other comments about this survey below:

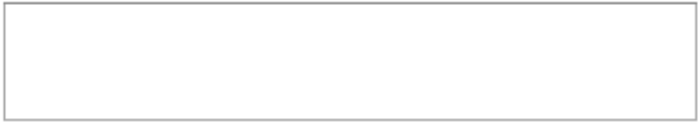

Back / Submit 


\section{Appendix C-Occupant Survey Results}

Results are presented below for occupants who selected either the GSA standard or WS fixtures as their workspace lighting system. Percentages are calculated out of the number of people with each lighting system who responded to each question. In the interest of space, some questions have been shortened somewhat in the table below. Complete text can be found in the survey itself (Appendix B).

\begin{tabular}{|c|c|c|c|c|c|}
\hline & & $\begin{array}{l}\text { Number } 0 \\
\text { responder }\end{array}$ & & $\begin{array}{l}\text { Percentag } \\
\text { responde }\end{array}$ & \\
\hline Question & Answer choices & $\begin{array}{l}\text { GSA } \\
\text { standard }\end{array}$ & WS & $\begin{array}{l}\text { GSA } \\
\text { standard }\end{array}$ & WS \\
\hline & 30 or under & 0 & 7 & $0 \%$ & $15 \%$ \\
\hline & $31-40$ & 4 & 8 & $33 \%$ & $17 \%$ \\
\hline What is your & $41-50$ & 4 & 10 & $33 \%$ & $21 \%$ \\
\hline & Over 50 & 4 & 22 & $33 \%$ & $47 \%$ \\
\hline & Total & 12 & 47 & $100 \%$ & $100 \%$ \\
\hline & Female & 6 & 24 & $50 \%$ & $50 \%$ \\
\hline What is your & Male & 6 & 24 & $50 \%$ & $50 \%$ \\
\hline & Total & 12 & 48 & $100 \%$ & $100 \%$ \\
\hline On a typical day, & More than 6 hours & 11 & 39 & $92 \%$ & $81 \%$ \\
\hline how long are & $4-6$ hours & 1 & 9 & $8 \%$ & $19 \%$ \\
\hline you in your & 2-4 hours & 0 & 0 & $0 \%$ & $0 \%$ \\
\hline personal & Less than 2 hours & 0 & 0 & $0 \%$ & $0 \%$ \\
\hline workspace? & Total & 12 & 48 & $100 \%$ & $100 \%$ \\
\hline Are you able to & Yes & 4 & 12 & $33 \%$ & $25 \%$ \\
\hline see out a & No & 8 & 36 & $67 \%$ & $75 \%$ \\
\hline $\begin{array}{l}\text { sitting in your } \\
\text { workspace? }\end{array}$ & Total & 12 & 48 & $100 \%$ & $100 \%$ \\
\hline & Yes & 2 & 8 & $17 \%$ & $17 \%$ \\
\hline 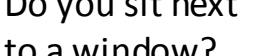 & No & 10 & 39 & $83 \%$ & $83 \%$ \\
\hline & Total & 12 & 47 & $100 \%$ & $100 \%$ \\
\hline Which of the & Cubicles in open area & 12 & 48 & $100 \%$ & $100 \%$ \\
\hline following best & Enclosed private office & 0 & 0 & $0 \%$ & $0 \%$ \\
\hline $\begin{array}{l}\text { personal } \\
\text { workspace? }\end{array}$ & Total & 12 & 48 & $100 \%$ & $100 \%$ \\
\hline Overall, is the & Yes & 6 & 33 & $55 \%$ & $70 \%$ \\
\hline lighting & No & 5 & 14 & $45 \%$ & $30 \%$ \\
\hline comfortable? & Total & 11 & 47 & $100 \%$ & $100 \%$ \\
\hline Which of the & (Picture of atroffer fixture) & 0 & 0 & $0 \%$ & $0 \%$ \\
\hline $\begin{array}{l}\text { following } \\
\text { fixtures most }\end{array}$ & $\begin{array}{l}\text { (Picture of a continuous } \\
\text { direct/indirect fixture) }\end{array}$ & 12 & 0 & $100 \%$ & $0 \%$ \\
\hline closely & (Picture of a WS fixture) & 0 & 48 & $0 \%$ & $100 \%$ \\
\hline resembles the & Total & 12 & 48 & $100 \%$ & $100 \%$ \\
\hline
\end{tabular}




\begin{tabular}{|c|c|c|c|c|c|}
\hline $\begin{array}{l}\text { general lighting } \\
\text { in your } \\
\text { immediate } \\
\text { workspace? }\end{array}$ & & & & & \\
\hline \multirow{7}{*}{$\begin{array}{l}\text { My work surface } \\
\text { is evenly lighted } \\
\text { without very } \\
\text { bright or dim } \\
\text { spots. }\end{array}$} & Strongly disagree & 2 & 5 & $17 \%$ & $10 \%$ \\
\hline & Disagree & 4 & 7 & $33 \%$ & $15 \%$ \\
\hline & Neutral & 1 & 9 & $8 \%$ & $19 \%$ \\
\hline & Agree & 4 & 19 & $33 \%$ & $40 \%$ \\
\hline & Strongly agree & 1 & 8 & $8 \%$ & $17 \%$ \\
\hline & Does not apply & 0 & 0 & $0 \%$ & $0 \%$ \\
\hline & Total & 12 & 48 & $100 \%$ & $100 \%$ \\
\hline \multirow{7}{*}{$\begin{array}{l}\text { The lighting } \\
\text { fixtures in the } \\
\text { general office } \\
\text { area around my } \\
\text { workspace are } \\
\text { nice-looking. }\end{array}$} & Strongly disagree & 1 & 2 & $8 \%$ & $4 \%$ \\
\hline & Disagree & 2 & 3 & $17 \%$ & $6 \%$ \\
\hline & Neutral & 5 & 12 & $42 \%$ & $25 \%$ \\
\hline & Agree & 4 & 22 & $33 \%$ & $46 \%$ \\
\hline & Strongly agree & 0 & 9 & $0 \%$ & $19 \%$ \\
\hline & Does not apply & 0 & 0 & $0 \%$ & $0 \%$ \\
\hline & Total & 12 & 48 & $100 \%$ & $100 \%$ \\
\hline \multirow{7}{*}{$\begin{array}{l}\text { The light fixtures } \\
\text { are too bright. }\end{array}$} & Strongly disagree & 1 & 9 & $8 \%$ & $19 \%$ \\
\hline & Disagree & 7 & 23 & $58 \%$ & $48 \%$ \\
\hline & Neutral & 3 & 8 & $25 \%$ & $17 \%$ \\
\hline & Agree & 1 & 5 & $8 \%$ & $10 \%$ \\
\hline & Strongly agree & 0 & 2 & $0 \%$ & $4 \%$ \\
\hline & Does not apply & 0 & 1 & $0 \%$ & $2 \%$ \\
\hline & Total & 12 & 48 & $100 \%$ & $100 \%$ \\
\hline \multirow{7}{*}{$\begin{array}{l}\text { The lighting } \\
\text { control system } \\
\text { allows me to } \\
\text { create the } \\
\text { lighting } \\
\text { conditions I } \\
\text { want. }\end{array}$} & Strongly disagree & 6 & 12 & $50 \%$ & $25 \%$ \\
\hline & Disagree & 3 & 13 & $25 \%$ & $27 \%$ \\
\hline & Neutral & 1 & 5 & $8 \%$ & $10 \%$ \\
\hline & Agree & 0 & 5 & $0 \%$ & $10 \%$ \\
\hline & Strongly agree & 0 & 3 & $0 \%$ & $6 \%$ \\
\hline & Does not apply & 2 & 10 & $17 \%$ & $21 \%$ \\
\hline & Total & 12 & 48 & $100 \%$ & $100 \%$ \\
\hline \multirow{7}{*}{$\begin{array}{l}\text { The lighting } \\
\text { feels gloomy. }\end{array}$} & Strongly disagree & 1 & 9 & $8 \%$ & $19 \%$ \\
\hline & Disagree & 3 & 16 & $25 \%$ & $33 \%$ \\
\hline & Neutral & 5 & 7 & $42 \%$ & $15 \%$ \\
\hline & Agree & 2 & 9 & $17 \%$ & $19 \%$ \\
\hline & Strongly agree & 1 & 6 & $8 \%$ & $13 \%$ \\
\hline & Does not apply & 0 & 1 & $0 \%$ & $2 \%$ \\
\hline & Total & 12 & 48 & $100 \%$ & $100 \%$ \\
\hline \multirow{7}{*}{$\begin{array}{l}\text { The lights flicker } \\
\text { throughout the } \\
\text { day. }\end{array}$} & Strongly disagree & 5 & 12 & $45 \%$ & $26 \%$ \\
\hline & Disagree & 3 & 20 & $27 \%$ & $43 \%$ \\
\hline & Neutral & 3 & 4 & $27 \%$ & $9 \%$ \\
\hline & Agree & 0 & 5 & $0 \%$ & $11 \%$ \\
\hline & Strongly agree & 0 & 1 & $0 \%$ & $2 \%$ \\
\hline & Does not apply & 0 & 5 & $0 \%$ & $11 \%$ \\
\hline & Total & 11 & 47 & $100 \%$ & $100 \%$ \\
\hline
\end{tabular}




\begin{tabular}{|c|c|c|c|c|c|}
\hline \multirow{7}{*}{$\begin{array}{l}\text { The lighting } \\
\text { helps create a } \\
\text { good image for } \\
\text { the } \\
\text { organization. }\end{array}$} & Strongly disagree & 1 & 5 & $9 \%$ & $10 \%$ \\
\hline & Disagree & 2 & 7 & $18 \%$ & $15 \%$ \\
\hline & Neutral & 6 & 15 & $55 \%$ & $31 \%$ \\
\hline & Agree & 2 & 13 & $18 \%$ & $27 \%$ \\
\hline & Strongly agree & 0 & 8 & $0 \%$ & $17 \%$ \\
\hline & Does not apply & 0 & 0 & $0 \%$ & $0 \%$ \\
\hline & Total & 11 & 48 & $100 \%$ & $100 \%$ \\
\hline \multirow{7}{*}{$\begin{array}{l}\text { My skin is an } \\
\text { unnatural tone } \\
\text { under the } \\
\text { lighting. }\end{array}$} & Strongly disagree & 2 & 4 & $18 \%$ & $9 \%$ \\
\hline & Disagree & 1 & 17 & $9 \%$ & $37 \%$ \\
\hline & Neutral & 7 & 20 & $64 \%$ & $43 \%$ \\
\hline & Agree & 1 & 3 & $9 \%$ & $7 \%$ \\
\hline & Strongly agree & 0 & 2 & $0 \%$ & $4 \%$ \\
\hline & Does not apply & 0 & 0 & $0 \%$ & $0 \%$ \\
\hline & Total & 11 & 46 & $100 \%$ & $100 \%$ \\
\hline \multirow{7}{*}{$\begin{array}{l}\text { The room } \\
\text { surfaces (walls, } \\
\text { ceilings) have a } \\
\text { pleasant } \\
\text { brightness. }\end{array}$} & Strongly disagree & 2 & 4 & $17 \%$ & $9 \%$ \\
\hline & Disagree & 3 & 13 & $25 \%$ & $28 \%$ \\
\hline & Neutral & 2 & 10 & $17 \%$ & $21 \%$ \\
\hline & Agree & 5 & 14 & $42 \%$ & $30 \%$ \\
\hline & Strongly agree & 0 & 4 & $0 \%$ & $9 \%$ \\
\hline & Does not apply & 0 & 2 & $0 \%$ & $4 \%$ \\
\hline & Total & 12 & 47 & $100 \%$ & $100 \%$ \\
\hline \multirow{7}{*}{$\begin{array}{l}\text { How would you } \\
\text { rate the lighting } \\
\text { in your } \\
\text { workplace for } \\
\text { reading from } \\
\text { paper? }\end{array}$} & Much too bright & 0 & 1 & $0 \%$ & $2 \%$ \\
\hline & Too bright & 2 & 4 & $18 \%$ & $8 \%$ \\
\hline & Just right & 7 & 30 & $64 \%$ & $63 \%$ \\
\hline & Too dim & 1 & 10 & $9 \%$ & $21 \%$ \\
\hline & Much too dim & 1 & 3 & $9 \%$ & $6 \%$ \\
\hline & Does not apply & 0 & 0 & $0 \%$ & $0 \%$ \\
\hline & Total & 11 & 48 & $100 \%$ & $100 \%$ \\
\hline \multirow{7}{*}{$\begin{array}{l}\text { How would you } \\
\text { rate the lighting } \\
\text { in your } \\
\text { workplace for } \\
\text { reading from a } \\
\text { computer } \\
\text { screen? }\end{array}$} & Much too bright & 0 & 1 & $0 \%$ & $2 \%$ \\
\hline & Too bright & 3 & 7 & $27 \%$ & $15 \%$ \\
\hline & Just right & 6 & 33 & $55 \%$ & $69 \%$ \\
\hline & Too dim & 2 & 6 & $18 \%$ & $13 \%$ \\
\hline & Much too dim & 0 & 1 & $0 \%$ & $2 \%$ \\
\hline & Does not apply & 0 & 0 & $0 \%$ & $0 \%$ \\
\hline & Total & 11 & 48 & $100 \%$ & $100 \%$ \\
\hline \multirow{7}{*}{$\begin{array}{l}\text { How would you } \\
\text { rate the lighting } \\
\text { in your } \\
\text { workplace for } \\
\text { writing on } \\
\text { paper? }\end{array}$} & Much too bright & 0 & 1 & $0 \%$ & $2 \%$ \\
\hline & Too bright & 1 & 3 & $9 \%$ & $6 \%$ \\
\hline & Just right & 8 & 35 & $73 \%$ & $73 \%$ \\
\hline & Too dim & 1 & 7 & $9 \%$ & $15 \%$ \\
\hline & Much too dim & 1 & 2 & $9 \%$ & $4 \%$ \\
\hline & Does not apply & 0 & 0 & $0 \%$ & $0 \%$ \\
\hline & Total & 11 & 48 & $100 \%$ & $100 \%$ \\
\hline \multirow{4}{*}{$\begin{array}{l}\text { How would you } \\
\text { rate the lighting } \\
\text { in your } \\
\text { workplace for }\end{array}$} & Much too bright & 0 & 1 & $0 \%$ & $2 \%$ \\
\hline & Too bright & 0 & 1 & $0 \%$ & $2 \%$ \\
\hline & Just right & 10 & 39 & $91 \%$ & $81 \%$ \\
\hline & Too dim & 1 & 7 & $9 \%$ & $15 \%$ \\
\hline
\end{tabular}




\begin{tabular}{|c|c|c|c|c|c|}
\hline \multirow{3}{*}{$\begin{array}{l}\text { typing on a } \\
\text { keyboard? }\end{array}$} & Much too dim & 0 & 0 & $0 \%$ & $0 \%$ \\
\hline & Does not apply & 0 & 0 & $0 \%$ & $0 \%$ \\
\hline & Total & 11 & 48 & $100 \%$ & $100 \%$ \\
\hline \multirow{7}{*}{$\begin{array}{l}\text { How would you } \\
\text { rate the lighting } \\
\text { in your } \\
\text { workplace for } \\
\text { using the } \\
\text { telephone? }\end{array}$} & Much too bright & 0 & 1 & $0 \%$ & $2 \%$ \\
\hline & Too bright & 1 & 0 & $9 \%$ & $0 \%$ \\
\hline & Just right & 7 & 44 & $64 \%$ & $92 \%$ \\
\hline & Too dim & 2 & 2 & $18 \%$ & $4 \%$ \\
\hline & Much too dim & 1 & 1 & $9 \%$ & $2 \%$ \\
\hline & Does not apply & 0 & 0 & $0 \%$ & $0 \%$ \\
\hline & Total & 11 & 48 & $100 \%$ & $100 \%$ \\
\hline \multirow{7}{*}{$\begin{array}{l}\text { How would you } \\
\text { rate the lighting } \\
\text { in your } \\
\text { workplace for } \\
\text { filing or locating } \\
\text { papers? }\end{array}$} & Much too bright & 0 & 1 & $0 \%$ & $2 \%$ \\
\hline & Too bright & 1 & 0 & $9 \%$ & $0 \%$ \\
\hline & Just right & 8 & 36 & $73 \%$ & $75 \%$ \\
\hline & Too dim & 2 & 9 & $18 \%$ & $19 \%$ \\
\hline & Much too dim & 0 & 1 & $0 \%$ & $2 \%$ \\
\hline & Does not apply & 0 & 1 & $0 \%$ & $2 \%$ \\
\hline & Total & 11 & 48 & $100 \%$ & $100 \%$ \\
\hline \multirow{7}{*}{$\begin{array}{l}\text { How would you } \\
\text { rate the lighting } \\
\text { in your } \\
\text { workplace for } \\
\text { face to face } \\
\text { conversations? }\end{array}$} & Much too bright & 0 & 1 & $0 \%$ & $2 \%$ \\
\hline & Too bright & 1 & 3 & $10 \%$ & $6 \%$ \\
\hline & Just right & 8 & 43 & $80 \%$ & $90 \%$ \\
\hline & Too dim & 1 & 1 & $10 \%$ & $2 \%$ \\
\hline & Much too dim & 0 & 0 & $0 \%$ & $0 \%$ \\
\hline & Does not apply & 0 & 0 & $0 \%$ & $0 \%$ \\
\hline & Total & 10 & 48 & $100 \%$ & $100 \%$ \\
\hline \multirow{6}{*}{$\begin{array}{l}\text { How often do } \\
\text { you experience } \\
\text { glare reflected } \\
\text { from your work } \\
\text { surface? }\end{array}$} & Never & 1 & 17 & $9 \%$ & $35 \%$ \\
\hline & Rarely & 4 & 14 & $36 \%$ & $29 \%$ \\
\hline & Sometimes & 4 & 13 & $36 \%$ & $27 \%$ \\
\hline & Often & 1 & 4 & $9 \%$ & $8 \%$ \\
\hline & Always & 1 & 0 & $9 \%$ & $0 \%$ \\
\hline & Total & 11 & 48 & $100 \%$ & $100 \%$ \\
\hline \multirow{6}{*}{$\begin{array}{l}\text { How often do } \\
\text { you experience } \\
\text { glare from the } \\
\text { light fixtures } \\
\text { reflected on } \\
\text { your computer } \\
\text { screen? }\end{array}$} & Never & 2 & 20 & $18 \%$ & $42 \%$ \\
\hline & Rarely & 3 & 17 & $27 \%$ & $35 \%$ \\
\hline & Sometimes & 4 & 7 & $36 \%$ & $15 \%$ \\
\hline & Often & 1 & 2 & $9 \%$ & $4 \%$ \\
\hline & Always & 1 & 2 & $9 \%$ & $4 \%$ \\
\hline & Total & 11 & 48 & $100 \%$ & $100 \%$ \\
\hline \multirow{6}{*}{$\begin{array}{l}\text { How often do } \\
\text { you experience } \\
\text { glare from the } \\
\text { window } \\
\text { reflected on } \\
\text { your computer } \\
\text { screen? }\end{array}$} & Never & 9 & 33 & $90 \%$ & $70 \%$ \\
\hline & Rarely & 0 & 4 & $0 \%$ & $9 \%$ \\
\hline & Sometimes & 1 & 6 & $10 \%$ & $13 \%$ \\
\hline & Often & 0 & 4 & $0 \%$ & $9 \%$ \\
\hline & Always & 0 & 0 & $0 \%$ & $0 \%$ \\
\hline & Total & 10 & 47 & $100 \%$ & $100 \%$ \\
\hline \multirow{2}{*}{$\begin{array}{l}\text { How often do } \\
\text { you experience }\end{array}$} & Never & 4 & 19 & $40 \%$ & $40 \%$ \\
\hline & Rarely & 1 & 17 & $10 \%$ & $35 \%$ \\
\hline
\end{tabular}




\begin{tabular}{|c|c|c|c|c|c|}
\hline \multirow{4}{*}{$\begin{array}{l}\text { overhead glare } \\
\text { from the general } \\
\text { lighting? }\end{array}$} & Sometimes & 3 & 8 & $30 \%$ & $17 \%$ \\
\hline & Often & 1 & 3 & $10 \%$ & $6 \%$ \\
\hline & Always & 1 & 1 & $10 \%$ & $2 \%$ \\
\hline & Total & 10 & 48 & $100 \%$ & $100 \%$ \\
\hline \multirow{6}{*}{$\begin{array}{l}\text { How often do } \\
\text { you experience } \\
\text { glare from your } \\
\text { task lighting? }\end{array}$} & Never & 3 & 22 & $38 \%$ & $46 \%$ \\
\hline & Rarely & 1 & 14 & $13 \%$ & $29 \%$ \\
\hline & Sometimes & 2 & 8 & $25 \%$ & $17 \%$ \\
\hline & Often & 1 & 4 & $13 \%$ & $8 \%$ \\
\hline & Always & 1 & 0 & $13 \%$ & $0 \%$ \\
\hline & Total & 8 & 48 & $100 \%$ & $100 \%$ \\
\hline \multirow{6}{*}{$\begin{array}{l}\text { How often do } \\
\text { you experience } \\
\text { direct glare from } \\
\text { a window? }\end{array}$} & Never & 7 & 39 & $78 \%$ & $81 \%$ \\
\hline & Rarely & 1 & 2 & $11 \%$ & $4 \%$ \\
\hline & Sometimes & 1 & 5 & $11 \%$ & $10 \%$ \\
\hline & Often & 0 & 2 & $0 \%$ & $4 \%$ \\
\hline & Always & 0 & 0 & $0 \%$ & $0 \%$ \\
\hline & Total & 9 & 48 & $100 \%$ & $100 \%$ \\
\hline \multirow{6}{*}{$\begin{array}{l}\text { How often do } \\
\text { you experience } \\
\text { direct glare from } \\
\text { the light } \\
\text { fixtures? }\end{array}$} & Never & 4 & 22 & $40 \%$ & $46 \%$ \\
\hline & Rarely & 2 & 16 & $20 \%$ & $33 \%$ \\
\hline & Sometimes & 2 & 8 & $20 \%$ & $17 \%$ \\
\hline & Often & 1 & 2 & $10 \%$ & $4 \%$ \\
\hline & Always & 1 & 0 & $10 \%$ & $0 \%$ \\
\hline & Total & 10 & 48 & $100 \%$ & $100 \%$ \\
\hline \multirow{7}{*}{$\begin{array}{l}\text { What is the } \\
\text { color } \\
\text { appearance of } \\
\text { the lighting in } \\
\text { your personal } \\
\text { workspace? }\end{array}$} & Very warm & 2 & 5 & $18 \%$ & $10 \%$ \\
\hline & Somewhat warm & 1 & 5 & $9 \%$ & $10 \%$ \\
\hline & Neutral & 3 & 17 & $27 \%$ & $35 \%$ \\
\hline & Somewhat cold & 4 & 14 & $36 \%$ & $29 \%$ \\
\hline & Very cold & 0 & 5 & $0 \%$ & $10 \%$ \\
\hline & Don't know & 1 & 2 & $9 \%$ & $4 \%$ \\
\hline & Total & 11 & 48 & $100 \%$ & $100 \%$ \\
\hline \multirow{7}{*}{$\begin{array}{l}\text { What would you } \\
\text { prefer for the } \\
\text { color } \\
\text { appearance of } \\
\text { the lighting in } \\
\text { your personal } \\
\text { workspace? }\end{array}$} & Very warm & 0 & 9 & $0 \%$ & $19 \%$ \\
\hline & Somewhat warm & 0 & 3 & $0 \%$ & $6 \%$ \\
\hline & Neutral & 1 & 9 & $9 \%$ & $19 \%$ \\
\hline & Somewhat cold & 8 & 13 & $73 \%$ & $27 \%$ \\
\hline & Very cold & 2 & 12 & $18 \%$ & $25 \%$ \\
\hline & Don't know & 0 & 2 & $0 \%$ & $4 \%$ \\
\hline & Total & 11 & 48 & $100 \%$ & $100 \%$ \\
\hline \multirow{6}{*}{$\begin{array}{l}\text { How often do } \\
\text { you experience } \\
\text { "burning" or } \\
\text { tired eyes after } \\
\text { reading } \\
\text { extensively? }\end{array}$} & Never & 0 & 8 & $0 \%$ & $17 \%$ \\
\hline & Rarely & 3 & 13 & $27 \%$ & $28 \%$ \\
\hline & About once per month & 2 & 4 & $18 \%$ & $9 \%$ \\
\hline & About once per week & 3 & 12 & $27 \%$ & $26 \%$ \\
\hline & About once a day & 3 & 10 & $27 \%$ & $21 \%$ \\
\hline & Total & 11 & 47 & $100 \%$ & $100 \%$ \\
\hline \multirow{4}{*}{$\begin{array}{l}\text { How often do } \\
\text { you experience } \\
\text { "burning" or } \\
\text { tired eyes after }\end{array}$} & Never & 0 & 6 & $0 \%$ & $13 \%$ \\
\hline & Rarely & 3 & 9 & $27 \%$ & $19 \%$ \\
\hline & About once per month & 1 & 8 & $9 \%$ & $17 \%$ \\
\hline & About once per week & 2 & 12 & $18 \%$ & $26 \%$ \\
\hline
\end{tabular}




\begin{tabular}{|c|c|c|c|c|c|}
\hline \multirow{2}{*}{$\begin{array}{l}\text { using a } \\
\text { computer } \\
\text { extensively? }\end{array}$} & About once a day & 5 & 12 & $45 \%$ & $26 \%$ \\
\hline & Total & 11 & 47 & $100 \%$ & $100 \%$ \\
\hline \multirow{6}{*}{$\begin{array}{l}\text { How often do } \\
\text { you have to } \\
\text { take a break to } \\
\text { let your eyes } \\
\text { recover? }\end{array}$} & Never & 0 & 7 & $0 \%$ & $15 \%$ \\
\hline & Rarely & 2 & 6 & $18 \%$ & $13 \%$ \\
\hline & About once per month & 0 & 11 & $0 \%$ & $23 \%$ \\
\hline & About once per week & 3 & 5 & $27 \%$ & $11 \%$ \\
\hline & About once a day & 6 & 18 & $55 \%$ & $38 \%$ \\
\hline & Total & 11 & 47 & $100 \%$ & $100 \%$ \\
\hline \multirow{6}{*}{$\begin{array}{l}\text { How often do } \\
\text { you experience } \\
\text { a headache that } \\
\text { you think is } \\
\text { caused by your } \\
\text { lighting? }\end{array}$} & Never & 4 & 19 & $40 \%$ & $40 \%$ \\
\hline & Rarely & 1 & 15 & $10 \%$ & $32 \%$ \\
\hline & About once per month & 2 & 5 & $20 \%$ & $11 \%$ \\
\hline & About once per week & 3 & 4 & $30 \%$ & $9 \%$ \\
\hline & About once a day & 0 & 4 & $0 \%$ & $9 \%$ \\
\hline & Total & 10 & 47 & $100 \%$ & $100 \%$ \\
\hline \multirow{12}{*}{$\begin{array}{l}\text { If you could } \\
\text { change the } \\
\text { lighting in your } \\
\text { office, what } \\
\text { would you do? } \\
\text { Please check all } \\
\text { that apply. }\end{array}$} & $\begin{array}{l}\text { Change fixture location } \\
\text { relative to workstation }\end{array}$ & 5 & 10 & $45 \%$ & $21 \%$ \\
\hline & $\begin{array}{l}\text { Make general lighting } \\
\text { fixtures produce more light }\end{array}$ & 4 & 12 & $36 \%$ & $26 \%$ \\
\hline & $\begin{array}{l}\text { Make general lighting } \\
\text { fixtures less glary }\end{array}$ & 2 & 7 & $18 \%$ & $15 \%$ \\
\hline & $\begin{array}{l}\text { Change the appearance of } \\
\text { the fixtures }\end{array}$ & 2 & 3 & $18 \%$ & $6 \%$ \\
\hline & $\begin{array}{l}\text { Change the color } \\
\text { appearance of the light }\end{array}$ & 2 & 12 & $18 \%$ & $26 \%$ \\
\hline & Add a task light & 5 & 15 & $45 \%$ & $32 \%$ \\
\hline & $\begin{array}{l}\text { Be able to control light level } \\
\text { with a dimmer or high/low } \\
\text { switch }\end{array}$ & 6 & 28 & $55 \%$ & $60 \%$ \\
\hline & $\begin{array}{l}\text { Get better access to a } \\
\text { window view }\end{array}$ & 4 & 24 & $36 \%$ & $51 \%$ \\
\hline & Get better access to daylight & 5 & 27 & $45 \%$ & $57 \%$ \\
\hline & $\begin{array}{l}\text { Have bulbs replaced and } \\
\text { fixtures repaired faster }\end{array}$ & 1 & 3 & $9 \%$ & $6 \%$ \\
\hline & I would not change anything & 0 & 8 & $0 \%$ & $17 \%$ \\
\hline & Total respondents & 11 & 47 & $100 \%$ & $100 \%$ \\
\hline
\end{tabular}

